\title{
Geschäftsmodelle von Landes- und Kantonalbanken im Detailvergleich: eine referenzwert-gestützte Clusteranalyse
}
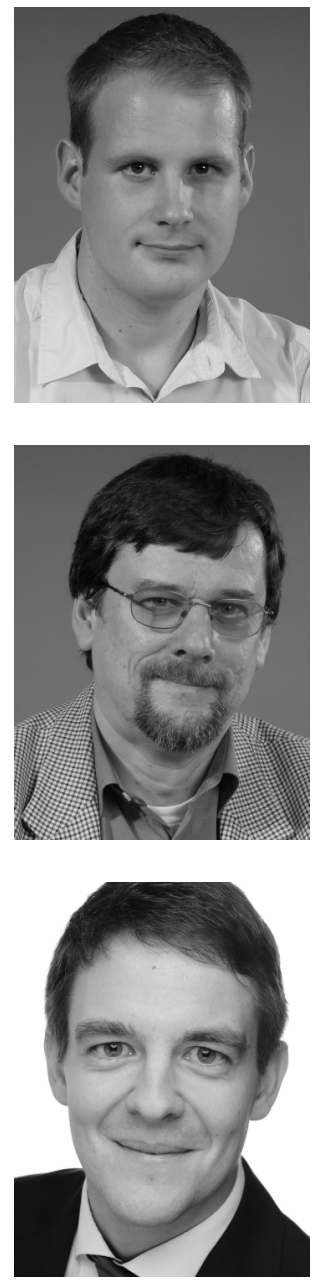

\section{Toni Richter, Horst Gischer und Florian Schierhorn}

In der anhaltenden Diskussion um die Zukunft der deutschen Landesbanken untersucht der Beitrag, inwieweit die mit ähnlichen Aufgaben betrauten schweizerischen Kantonalbanken als ein geeignetes geschäftsstrategisches Vorbild dienen können. In einem dreistufigen Analyseprozess erfolgt zunächst deskriptiv-statistisch die dezidierte Aufarbeitung der jeweiligen nationalen Rahmenbedingungen, der zentralen Charakteristika und der (gesetzlichen) Alleinstellungsmerkmale. Darauf aufbauend werden die Geschäftsmodelle beider Bankengruppen - erstmalig in der Literatur - auf Basis eines referenzwert-gestützten Clusteralgorithmus identifiziert, kategorisierend eingeordnet und im Zeitverlauf (2000, 2007, 2014) erfasst. Inwiefern die so zielführend gegeneinander abgegrenzten Geschäftsmodelle mit systematischen Unterschieden in der Performance verbunden sind, wird im letzten Schritt allen voran anhand einer „Adjustierten Cost-Income-Ratio“ geprüft. Unsere Ergebnisse zeigen, dass die Kantonalbanken in den 15 Untersuchungsjahren wesentlich stärker im klassischen einlagenbasierten Kreditgeschäft aktiv waren und dabei zwar stets eine geringere Rentabilität erzielten, aber durchweg stabiler und produktiver operierten als die Landesbanken mit Fokussierung auf das Investmentbanking.

This paper contributes to the current discussion about the future of the German "Landesbanken" by analyzing how the Swiss "Kantonalbanken" can serve as strategic model for the former. The analysis consists of three steps: First, the national framework, the main characteristics and the judicial specificities are presented for both types of banks, respectively. Second, -unprecedented in the economic literature- both bank groups' business models are identitfied with the help of a reference-based cluster algorithm, categorized and documented over the course of time $(2000,2007,2014)$. In a last step, the extent to which variation in the business models is correlated with systematic differences in the banks' performance is examined by constructing an "adjusted cost-income ratio". Our results show that in the last 15 years, "Kantonalbanken" have been much more engaged in classic deposit-based lending activities than their German "Landesbanken" counterparts which had a focus in investment banking. Although their profitability fell short of the one of the "Landesbanken", the "Kantonalbanken" have been characterized by greater stability and higher productivity. 
Geschäftsmodelle, Kantonalbanken, Landesbanken, Leistungsfähigkeit, Clusterverfahren Business Models, Cantonal Banks, Landesbanken, Performance, Cluster Analysis

\section{Motivation}

Am 31. März 2014 verkündete der Deutsche Sparkassen- und Giroverband (DSGV) die Aufnahme des Verbandes der Schweizerischen Kantonalbanken (VSKB) als ausserordentliches Mitglied (DSGV 2014c). Während der DSGV als Dachverband die Belange der deutschen Sparkassen und Landesbanken (LB) vertritt, ist der VSKB die Interessenvertretung der schweizerischen Kantonalbanken (KB). Dabei sind die Kantone als Haupteigentümer das Pendant zu den deutschen Bundesländern, die nennenswerte Anteile an den LB halten. Beiden Bankengruppen ist gemein, Institute unter öffentlicher Kontrolle mit ähnlichen Geschäftszielen zu sein (Hess 2014).

Doch während die KB die Finanzkrise weitgehend unbeschadet überstanden haben und gegenwärtig erfolgreich im Umfeld der Niedrigzinsphase agieren, prägen ein hoher $\mathrm{Ab}$ schreibungsbedarf und eine anhaltende Ertragsschwäche die LB. Seit Jahren besteht in Politik und Wissenschaft Einigkeit, dass das bisherige Geschäftsmodell spätestens infolge der im Jahr 2005 abgeschafften staatlichen Haftungsgarantien nicht länger tragfähig ist. Wiederholt werden die Abkehr vom risikoträchtigen Investment-Banking als auch die horizontale und vertikale Konsolidierung innerhalb der Sparkassen-Finanzgruppe als Lösungsansätze gesehen (Noack 2009, 3; Schrooten 2009b, 20; Flesch 2010; Rudowicz 2013; Kaulvers 2015, 29ff.).

Freilich mangelt es diesem Diskurs zumeist an einer hinreichenden Abgrenzung des eigentlichen Untersuchungsobjekts - des Geschäftsmodells und seiner Rahmenbedingungen. So wird die vielschichtige unternehmerische Tätigkeit von Banken im Allgemeinen und der LB im Speziellen vorwiegend deskriptiv-statistisch erfasst. Je nach Intention des jeweiligen Verfassers werden unterschiedliche Merkmale ${ }^{1}$ in den Mittelpunkt gerückt, während es zugleich an wissenschaftlich fundierten Referenzwerten zur präzisen Einordnung der alternativen Geschäftsmodelle fehlt (Blundell-Wignall/Roulet 2013; Ayadi/de Groen 2014). Letztlich erschwert diese unzureichende methodische Stringenz gängiger Geschäftsmodellanalysen sowohl belastbare Vergleiche zwischen den Studienergebnissen als auch wissenschaftlich klar ableitbare Handlungsempfehlungen.

Dahingehend liegt der wesentliche Mehrwert des Beitrages konzeptionell in der innovativen Methodik zur strukturierten, harmonisierten Bestandsaufnahme von Geschäftsmodellen - eingebettet in den Kontext der Diskussion um die Zukunft der deutschen Landesbanken. Die zusätzlich in Form eines Vergleichs zu den schweizerischen Kantonalbanken geführte Auseinandersetzung folgt hierbei einem dreistufigen, ineinandergreifenden Analyseprozess:

(1) Erstens werden nationale Rahmenbedingungen, zentrale Charakteristika und Alleinstellungsmerkmale der Landes- und Kantonalbanken dezidiert aufgearbeitet.

(2) Zweitens schliesst sich als - Herzstück des Beitrages - die Identifizierung und kategorisierende Einordnung der Geschäftsmodelle im Zeitverlauf $(2000,2007,2014)$ auf Basis eines statistischen Clusterverfahrens an. Der innovative Algorithmus greift dabei

1 Vgl. die Arbeiten von Schildbach (2008, 9ff.); Martín et al. (2011, 124); von Zanthier (2015, 39ff.). 
auf gängige aktiv- wie passivseitige Bilanzgrößen als Ausdruck von strategischen Entscheidungen zurück. ${ }^{2}$

(3) Drittens wird mittels einer mehrdimensionalen Performanceanalyse (Rentabilität, Stabilität, Produktivität) der Frage nachgegangen, ob die unter (2) identifizierten, alternativen Geschäftsmodelle mit systematischen Unterschieden im Erfolg der Banken einhergehen. Erstmalig in der Literatur dient die im Vergleich zu gängigen Maßen verzerrungsarme „Adjustierte Cost-Income-Ratio“ (nach Gischer/Richter 2014) als zentrales Untersuchungskonzept.

Die Einordnung der Ergebnisse vor dem Hintergrund der Frage, inwiefern die Schweizer Institute als Vorbild für ihre deutschen Pendants dienen könnten, schliesst den Beitrag ab.

\section{Rahmenbedingungen und Charakteristika}

Wesentlichen Einfluss auf die Geschäftstätigkeit der Institute nehmen die Wettbewerbsverhältnisse, die rechtlichen Gegebenheiten und nicht zuletzt die Eigentümer-/Verbund-Strukturen (Deutsche Bundesbank 2015, 34). Die Landes- und Kantonalbanken weisen diesbezüglich wesentliche Gemeinsamkeiten aber auch signifikante Unterschiede auf.

\section{Nationales Umfeld}

In beiden Ländern operieren die Institute überwiegend als Universalbanken (Meier et al. 2013). und seit Jahren in einem Umfeld merklicher Marktkonsolidierung. Während die Anzahl der Institute in Deutschland von 2.764 im Jahr 2000 auf 1.830 in 2014 (- 33,8 \%) zurückging, reduzierten sich die eidgenössischen von 376 auf 276 (-26,6 \%). In beiden Regionen sank zugleich die Bankstellendichte ${ }^{3}$ : um 18,1\% im deutschen Raum und um $26,0 \%$ in der Schweiz.

Tabelle 1: Struktur der Bankensysteme

\begin{tabular}{llccccc}
\hline & \multicolumn{2}{l}{ Deutschland } & \multicolumn{3}{c}{ Schweiz } \\
\hline Rechtsgrundlage & KWG & & \multicolumn{3}{c}{ BankG } \\
Art des Bankensystems & Universal & & & \\
& & & & & \\
& 2000 & 2007 & 2014 & 2000 & 2007 & 2014 \\
\cline { 2 - 7 } GBS/BIP* & 2,9 & 3,0 & 2,7 & 4,6 & 6,0 & 4,7 \\
Banken & 2.764 & 2.037 & 1.830 & 376 & 331 & 276 \\
Bankstellen & 46.058 & 41.814 & 38.021 & 3.809 & 3.518 & 3.270 \\
Bankstellendichte & 56,0 & 50,8 & 45,9 & 53,0 & 46,6 & 39,2 \\
CR $_{5}$ & 20 & 22 & 32 & $66 *$ & 76 & 63
\end{tabular}

2 Als Grundlage dienen dabei die Arbeiten von Ayadilde Groen (2014) als auch von Roengpitya et al. (2014).

3 Die Bankstellendichte als Kenngröße für die Versorgung der Bevölkerung mit Finanzprodukten bestimmt sich als das Verhältnis zwischen den Einwohnern (je 100.000) eines Landes und der Anzahl an Bankfilialen.

4 Deutschland: Gesetz über das Kreditwesen; Schweiz: Bundesgesetz über die Banken und Sparkassen. 


\begin{tabular}{lcccccc}
\hline \multicolumn{3}{c}{ Deutschland } & \multicolumn{3}{c}{ Schweiz } \\
\hline HHI & 151 & 183 & 301 & $2.374^{* *}$ & 2.633 & 1.263 \\
$\begin{array}{l}\text { Einschätzung der Marktkon- } \\
\text { zentration }\end{array}$ & Gering & gering & gering & stark & stark & $\begin{array}{l}\text { mittel- } \\
\text { mässig }\end{array}$ \\
\hline
\end{tabular}

Quelle: EZB, Deutsche Bundesbank, Schweizer Nationalbank, Weltbank, Statistisches Bundesamt (Deutschland), Bundesamt für Statistik (Schweiz), eigene Berechnungen

Hinweise: *GBS = Gesamtbilanzsumme des Bankenmarktes, * Werte für 2002

Entsprechende Verschiebungen zeigen sich bei der Marktstruktur: Sowohl die Concentration Ratio $5\left(\mathrm{CR}_{5}\right)$ als auch der Herfindahl-Hirschman-Index ${ }^{5}(\mathrm{HHI})$ weisen eine zunehmende Konzentration der Heimatmärkte aus, wobei die LB in einem wettbewerbsintensiveren Umfeld als die KB zu operieren scheinen. ${ }^{6}$ Hierfür sprechen auch die Kalkulation des Lerner-Indexes, respektive des abgeleiteten Mark-Up als Marktergebnisgrößen im Rahmen von Kapitel IV (Tabelle 9). Diesbezüglich konnten die KB in 2014 (und in den Jahren zuvor) mehr als doppelt so hohe Preisaufschläge im klassischen Kreditgeschäft erzielen wie die LB.

Die deutsche Bankenlandschaft prägt dabei eine Drei-Säulen-Struktur. Neben den durchgängig privatwirtschaftlich organisierten Kreditbanken mit einem Marktanteil ${ }^{7}$ von 39\% agieren die öffentlich-rechtlichen Banken - Sparkassen/Landesbanken - mit $27 \%$ und der Genossenschaftssektor mit gegenwärtig $11 \%$. In der Schweiz dominieren die beiden Grossbanken UBS und Credit Suisse. Mit ca. 46 \% vereinen sie fast die Hälfte ihres Heimatmarktes auf sich. An zweiter Stelle stehen mit $17 \%$ Marktanteil die KB, gefolgt von den Regionalbanken/Sparkassen (4\%) und den Raiffeisenbanken (7\%).

\section{Rechtsform und Eigentümerstruktur}

Die $\mathrm{LB}^{8}$ sind in unterschiedlichen Rechtsformen ${ }^{9}$ organisiert. Heutzutage operieren sie entweder als rechtsfähige Anstalten des öffentlichen Rechts oder als privatrechtliche Aktiengesellschaften (AG). Ausserdem treten Mischformen in Form von Holdingmodellen auf (Siekmann 2011). Haupteigentümer der Geldhäuser sind dabei die jeweiligen Bundesländer sowie die regionalen Sparkassen- und Giroverbände. Entsprechend des schweizerischen BankG muss ein Kanton mit mehr als einem Drittel an jeder Kantonalbank beteiligt sein, wobei die öffentlich-rechtliche Anstalt oder die privatrechtliche Aktiengesellschaft als

5 Sowohl für die Concentration Ratio als auch für den Herfindahl-Hirschman-Index bildet die Bilanzsumme (Jahresendwert) die Berechnungsgrundlage auf Bankenebene.

6 Der Rückschluss von der Marktstruktur über das Marktverhalten - auf das Marktergebnis setzt die Gültigkeit des sogenannten Structure-Conduct-Performance-Paradigma nach Mason (1939) bzw. Bain (1951) voraus. Die jüngere Forschung lässt jedoch zumindest Zweifel an dieser Kausalkette erkennen, weshalb auf die wahren Wettbewerbsverhältnisse stets über das tatsächlich realisierte Marktergebnis abgesichert werden sollte (vgl. Richter et al. 2018). Entsprechendes wurde mit der Bestimmung des Lerner-Indexes im Rahmen von Kapitel III sichergestellt.

7 Gemessen an der Bilanzsumme; Daten: Deutsche Bundesbank (2014) bzw. Schweizer Nationalbank (2014).

8 Es ist anzumerken, dass die Bremer LB mittlerweile nicht mehr als rechtlich selbstständiges Institut operiert, wurde diese doch 2017 mit der NORD/LB vereinigt.

9 Die Rechtsgrundlage bilden neben dem KWG die jeweiligen Landesgesetze (Landesbank- und Sparkassengesetze) sowie Staatsverträge für den Fall, dass mehrere Bundesländer an einem Institut beteiligt sind (vgl. Tabelle 2). 
Tabelle 2: Bilanzsummen, Rechtsform und Eigentümerstruktur der LB und KB (2014)

\begin{tabular}{|c|c|c|c|c|}
\hline \multirow{9}{*}{$\begin{array}{l}\frac{c}{0} \\
\text { v } \\
\text { ग̃ } \\
\frac{0}{4} \\
\frac{d}{0} \\
\frac{c}{J}\end{array}$} & Finanzinstitut & BS* & Rechtsform & Eigentümer \\
\hline & $\begin{array}{l}\text { Landesbank Baden-Württemberg } \\
\text { (LBBW) }\end{array}$ & 266,2 & Anstalt des öffentlichen Rechts & $\begin{array}{lccc}\text { SV-BW } & (40,53 \%), & \text { Land BW } & (24,99 \%), \\
\text { Landeshauptstadt } & \text { Stuttgart } & (18,93 \%), \\
\text { Landesbeteiligungen } & \text { BW GmbH } & (13,54 \%), \\
\text { Landeskreditbank BW } & (2,01 \%)\end{array}$ \\
\hline & Bayerische Landesbank (Bayern LB) & 232,1 & Mischform & $\begin{array}{l}\text { BayernLB Holding AG }(100 \%) \text { : Freistaat BY } \\
(75 \%) \text {, SV-BY }(25 \%)\end{array}$ \\
\hline & $\begin{array}{l}\text { Norddeutsche Landesbank - } \\
\text { Girozentrale - (NORD/LB) }\end{array}$ & 197,6 & Anstalt des öffentlichen Rechts & $\begin{array}{l}\text { Land NI }(59,13 \%) \text {, Land ST }(5,57 \%) \text {, SV-NI } \\
(26,4 \%) \text {, Sparkassenbeteiligungszweck- } \\
\text { verband ST }(5,28 \%) \text { und MV }(3,68 \%)\end{array}$ \\
\hline & $\begin{array}{l}\text { Landesbank Hessen-Thüringen - } \\
\text { Girozentrale - (Helaba) }\end{array}$ & 179,5 & Anstalt des öffentlichen Rechts & $\begin{array}{l}\text { SV-HE-TH }(68,85 \%) \text { Land HE }(8,10 \%), \\
\text { Freistaat TH }(4,05 \%) \text {, Rheinischer SV, } \\
\text { Westfälisch-Lippischer SV, Fides Beta/ } \\
\text { Alpha GmbH (je 4,75\%) }\end{array}$ \\
\hline & HSH Nordbank AG & 110,1 & Privatrechtliche Aktiengesellschaft & $\begin{array}{l}\text { HSH Finanzfonds als Anstalt des öffentl. } \\
\text { Rechts der Länder SH und HH }(65,00 \%), \text { HH } \\
(10,80 \%) \text {, Land SH }(9,58 \%) \text {, SV-SH }(5,31 \%) \text {, } \\
\text { private Beteiligung }(9,31 \%)\end{array}$ \\
\hline & Landesbank Berlin AG & 57,4 & Mischform & $\begin{array}{l}\text { Landesbank B. Holding AG (100\%): } \\
\text { Erwerbsges. S-Finanzgruppe mbH \& Co. KG } \\
(89,37 \%) \text {, Beteiligungsges. S-Finanzgruppe } \\
\text { mbH \& Co. KG }(10,63 \%)\end{array}$ \\
\hline & $\begin{array}{l}\text { Bremer Landesbank Kreditanstalt } \\
\text { Oldenburg - Girozentrale - (Bremer LB) }\end{array}$ & 31,2 & Anstalt des öffentlichen Rechts & $\begin{array}{l}\text { Nord/LB }(54,83 \%), \quad H H \quad(41,20 \%), \quad \text { SV-NI } \\
(3,97 \%)\end{array}$ \\
\hline & Landesbank Saar (Saar LB) & 16,5 & Anstalt des öffentlichen Rechts & Land SL $(74,90 \%)$, SV-SL $(25,10 \%)$ \\
\hline \multirow{24}{*}{ 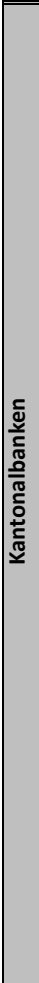 } & Zürcher Kantonalbank (ZH) & 147,3 & Sbst. Anstalt des kanton. öffentl. Rechts & Kanton Zürich (100 \%) \\
\hline & Banque Cantonale Vaudoise (VD) & 39,8 & Spezialgesetzliche AG & Kanton Waadt $(66,95 \%)$, Streubesitz** \\
\hline & Luzerner Kantonalbank (LU) & 28,5 & Rein privatrechtliche AG & Kanton Luzern $(61,50 \%)$, Streubesitz** \\
\hline & St. Galler Kantonalbank (SG) & 27 & Gemischtwirtschaftliche AG & Kanton St. Gallen (54,80 \%), Streubesitz** \\
\hline & Berner Kantonalbank (BE) & 26,7 & Rein privatrechtliche $A G$ & Kanton Bern $(51,50 \%)$, Streubesitz** \\
\hline & Basler Kantonalbank (BS) & 25,1 & Sbst. Anstalt des kanton. öffentl. Rechts & Kanton Basel-Stadt $(85,84 \%)$, Streubesitz ${ }^{* *}$ \\
\hline & Aargauische Kantonalbank (AG) & 22,2 & Sbst. Anstalt des kanton. öffentl. Rechts & Kanton Aargau (100 \%) \\
\hline & Basellandschaftliche Kantonalbank (BL) & 20,5 & Sbst. Anstalt des kanton. öffentl. Rechts & $\begin{array}{l}\text { Kanton Basel-Landschaft }(73,73 \%) \text {, } \\
\text { Streubesitz** }\end{array}$ \\
\hline & Graubündner Kantonalbank (GR) & 19,8 & Sbst. Anstalt des kanton. öffentl. Rechts & Kanton Graubünden $(84,4 \%)$, Streubesitz ${ }^{* *}$ \\
\hline & Thurgauer Kantonalbank (TG) & 18,7 & Sbst. Anstalt des kanton. öffentl. Rechts & Kanton Thurgau $(87,50 \%)$, Streubesitz** \\
\hline & Banque Cantonale de Fribourg (FR) & 17,7 & Sbst. Anstalt des kanton. öffentl. Rechts & Kanton Freiburg (100 \%) \\
\hline & Banque Cantonale de Genève (GE) & 16,6 & Spezialgesetzliche AG & $\begin{array}{l}\text { Kanton/Stadt/Pensionskasse Genf } \\
(44,27 \% / 20,87 \% / 5,96 \%) \\
44 \text { Gemeinden }(7,43 \%)\end{array}$ \\
\hline & Schwyzer Kantonalbank (SZ) & 14,4 & Sbst. Anstalt des kanton. öffentl. Rechts & Kanton Schwyz (100 \%) \\
\hline & Zuger Kantonalbank (ZG) & 13,3 & Spezialgeset & Kanton (50 \%), Streubesitz** \\
\hline & Banque Cantonale du Valais (VS) & 12,8 & Spezialgesetzliche Aktiengesellschaft & Kanton Wallis $(73,33 \%)$, Streubesitz ${ }^{* *}$ \\
\hline & Banca d. Stato del Cantone Ticino (TI) & 10,7 & Sbst. Anstalt des kanton. öffentl. Rechts & Kanton Tessin (100 \%) \\
\hline & Banque Cantonale Neuchâteloise (BN) & 9,3 & Sbst. Anstalt des kanton. öffentl. Rechts & Kanton Neuenburg (100 \%) \\
\hline & Schaffhauser Kantonalbank (SH) & 5,9 & Sbst. Anstalt des kanton. öffentl. Rechts & Kanton Schaffhausen (100 \%) \\
\hline & Glarner Kantonalbank (GL) & 4 & Spezialgesetzliche AG & Kanton Glarus $(68,26 \%)$, Streubesitz** \\
\hline & Obwaldner Kantonalt & 3,9 & Sbst. Anstalt des kanton. öffentl. Rechts & Kanton Obwalden $(78,57 \%)$, Streubesitz** \\
\hline & Nidwaldner Kantonalbank (NW) & 3,8 & Sbst. Anstalt des kanton. öffentl. Rechts & Kanton Nidwalden $(70,18 \%)$, Streubesitz ${ }^{* *}$ \\
\hline & Appenzeller Kantonalbank (AP) & 2,7 & Sbst. Anstalt des kanton. öffentl. Rechts & Kanton Appenzell (100 \%) \\
\hline & Urner Kantonalbank (UR) & 2,6 & Sbst. Anstalt des kanton. öffentl. Rechts & Kanton Uri (100 \%) \\
\hline & Banque Cantonale du Jura (JU) & 2,4 & Spezialgesetzliche AG & Kanton Jura $(55,56 \%)$, Streubesitz** \\
\hline
\end{tabular}

Quelle: Geschäftsberichte (2014) / Satzungen der Schweizer Nationalbank für die Kantonalbanken Hinweis: "Bilanzsumme in Mrd. Euro, eigene Umrechnungen, "* privatwirtschaftliche Partizipation $(j e<5 \%)$ 
Rechtsform voraussetzend sind (vgl. Tabelle 2). Bei der häufigsten Form ${ }^{10}$, der Selbständigen Anstalt des kantonalen öffentlichen Rechts, stattet der Kanton die Bank mit Eigenbzw. Dotationskapital aus. In einigen Fällen wird die stimmrechtslose Beteiligung von privaten Investoren über Partizipationsschein- bzw. Zertifikatskapital ermöglicht.

Bei den als Aktiengesellschaft firmierenden KB sind drei Formen zu unterscheiden: Die gemischtwirtschaftliche AG erlaubt es dem Kanton, sich neben Privaten an der Trägerschaft und Leitung zu beteiligen. ${ }^{11}$ Eine spezialgesetzliche AG untersteht nicht aktienrechtlichen Vorschriften, sofern die Gesellschaft unter Mitwirkung der öffentlichen Hand geleitet wird und der Kanton subsidiär haftet. Bei einer rein privatrechtlichen AG erhält der Kanton keine Sonderechte bei der Beteiligung und ist dem privaten Aktionär gleichgestellt.

\section{3. Öffentliche Aufgaben}

Unabhängig von der Rechtsform folgt aus dem öffentlich-rechtlichen Hintergrund beider Gruppen sachlogisch, „[...] dass jede staatliche Tätigkeit dem Gemeinwohl dienen und damit einen öffentlichen Zweck verfolgen muss.“ (Lampert 2010, 1467). Die Gewinnerzielung kann im Gegensatz zu privaten Instituten insofern nur eine notwendige Bedingung zur Erfüllung eines an der Gemeinnützigkeit orientierten Geschäftsmodells sein. Daher sind ineffiziente Strukturen, gewisse Risiken und Verzichte auf Erträge notfalls hinzunehmen (Piazza 2012, 89f.; Pfingsten et. al. 2014, 163). Die öffentlichen Aufgaben begrenzen als einzuhaltender Rahmen insofern nachdrücklich die Möglichkeiten zur Neuausrichtung des Geschäftsmodells der LB.

\section{a) Landesbanken - Öffentlicher Auftrag}

Den LB werden über Landesbankgesetze, Staatsverträge und den jeweiligen Satzungen öffentliche Aufgaben übertragen. Die Rechtsgrundlagen sind dabei unterschiedlich konkret und nicht einheitlich, ordnen den LB aber gemeinhin folgende Aufgaben zu (Gubitz 2013, 55f.; Staats 2006, 87ff.):

(1) Als Zentralbank der regionalen Sparkassen obliegt es den LB, für diese den bargeldlosen Zahlungsverkehr abzuwickeln.

(2) Im Rahmen des Subsidiaritätsprinzips unterstützen sie die kleineren kommunalen Bankeinheiten bei zu umfangreichen bzw. zu speziellen Geschäften.

(3) Die Wettbewerbssicherungsfunktion zielt vor allem auf strukturschwache Regionen mit wenigen Banken.

(4) In ihrer Funktion als Staats- und Kommunalbanken gelten sie als Hausbanken der jeweiligen öffentlichen Träger und führen für diese Bankdienstleistungen aus.

(5) Zudem wird bei einigen LB die Struktursicherungs- und Förderfunktion festgeschrieben (Berge et al. 2006, 78).

\section{b) Kantonalbanken - Leistungsauftrag}

Auch wenn es kein konstitutives Merkmal ist (Art. 3a BankG), so haben die KB doch den sogenannten Leistungsauftrag zu erfüllen, der teilweise in den Kantonsverfassungen und in

10 Rechtsgrundlage sind entweder die Verfassungen der Kantone oder die jeweiligen Kantonalbankgesetze.

11 Der Staat besitzt das Recht, Mitglieder des Verwaltungsrates und der Revisionsstelle zu ernennen. 
Zweckartikeln niedergeschrieben ist. ${ }^{12}$ Auch der Begriff des Leistungsauftrags wird in jedem Kanton unterschiedlich definiert. Folgende Funktionen sind diesem zugeordnet (Schwitter 2000, 128f.):

(1) Als Hausbank unterstützen sie die Kantone beim Zahlungsverkehr, der Depotverwaltung und bei der Anlage von Geldern und Ausgabe von Krediten.

(2) Ihnen obliegt im Rahmen der Gewährleistungsfunktion die flächendeckende Versorgung der Bevölkerung und Volkswirtschaft des Kantons mit Bankleistungen.

(3) Ferner haben die Banken eine Wettbewerbssicherungsfunktion inne.

(4) Die Förderfunktion besteht darin, sichere Anlagevarianten bereitzustellen, die das Sparbewusstsein und die Vermögensbildung der Bevölkerung anregen.

(5) Die Struktursicherung verpflichtet sie, die Wirtschaft im gesamten Kanton zu fördern.

(6) Die Sicherungsfunktion stellt auf den Einlagenschutz des risikoaversen Sparers ab.

(7) Letztlich sollen sie sich der Gesellschaft und der Umwelt verantwortlich fühlen.

\section{Staatsgarantie und Einlagensicherung}

Neben den gemeinwohlorientierten Aufgaben nehmen nicht zuletzt die Haftungsregelungen entscheidenden Einfluss auf die Geschäftstätigkeit öffentlicher-rechtlicher Banken. Wird in diesem Zusammenhang von Staatsgarantien gesprochen, so zielt dies auf die Anstaltslast $^{13}$ und die Gewährträgerhaftung ${ }^{14} \mathrm{ab}$.

\section{a) Landesbanken}

Entsprechend der Brüsseler Verständigung vom 17. Juli 2001 darf sich die finanzielle Beziehung zwischen Träger und Kreditinstitut nicht von einer privatwirtschaftlichen Eigentümerbeziehung unterscheiden. Dies führte zu einer Abschaffung der Gewährträgerhaftung, während die Anstaltslast dahingehend reduziert wird, dass wirtschaftliche Unterstützung nur im Rahmen der Beihilferegelungen des EG-Vertrages möglich ist. Schlussendlich „[...] besteht zwar weiterhin die öffentliche Trägerschaft, nicht jedoch das bisherige Haftungssystem, so dass die Institute im Insolvenzfall den gleichen Regeln unterworfen sind wie private“ (Brämer et al. 2010b, 208).

Damit greift bezüglich der Kundeneinlagen der LB - wie bei allen (deutschen) Banken das Einlagensicherungsgesetz (EinSiG) des Bundes. Es stellt einen Entschädigungsanspruch von $€ 100.000$ je Kunde sicher und sieht hierzu die Zugehörigkeit zu einem (gesetzlichen) Einlagensicherungssystem zwingend vor. Als ein solches anerkannt (nach $\mathbb{S} 43 \mathrm{EinSiG}$ ) ist der Haftungsverbund der S-Finanzgruppe: Dieses System der freiwilligen Institutssicherung schützt die angeschlossenen Institute (Sparkassen, Landesbanken, Landesbausparkassen) vor einer etwaigen Insolvenz und garantiert so faktisch die Sicherheit der Kundeneinlagen.

12 Eine Normierung des Leistungsauftrags fehlt einzig im Gesetz zur St. Galler Kantonalbank.

13 Allgemein ist die Anstaltslast „[...] die Verpflichtung eines Gewährträgers, das wirtschaftliche Fortbestehen der Anstalt zu gewährleisten und eventuelle Verluste auszugleichen“ (Engerer/Schrooten 2004, 6). Im Innenverhältnis zwischen Träger und Anstalt wird so auf die Zahlungsfähigkeit fokussiert (Brämer et al. 2010b, 207).

14 Allgemein beinhaltet die Gewährträgerhaftung „[...] die Haftung der Gebietskörperschaft, bei Insolvenz eines öffentlich-rechtlichen Kreditinstituts die Ansprüche der Gläubiger zu befriedigen“ (Engerer/ Schrooten 2004, 6) und bezieht sich daher auf das Aussenverhältnis zwischen Träger und Kreditinstitut. 


\section{b) Kantonalbanken}

Die Staatsgarantie ist seit Ende der 1990er Jahre nicht mehr zwingendes Merkmal einer jeden Kantonalbank (vgl. auch Art. 3a BankG). Dies ist die Folge einer Revision des BankG von 1999. Der Kanton kann selbstständig entscheiden, ob er für die Verbindlichkeiten seiner Bank unbeschränkt haftet, die Höhe einer allfälligen Abgeltung beschränkt oder gänzlich von einer Garantie absieht.

Tabelle 3: Staatsgarantie der Kantonalbanken

\begin{tabular}{ll}
\hline Art der Staatsgarantie & Banken \\
\hline unbeschränkt & FR, JU, BN, TI, VS, AG, AP, BL, BS, GL, GR, LU, NW, OW, SH, \\
& SZ, SG, TG, UR, ZG, ZH \\
beschränkt & GE \\
keine & VD, BE \\
\hline
\end{tabular}

Quelle: VSKB (2014), Abkürzungen der Kantonalbanken entsprechend der Tabelle 2.

Gegenwärtig besitzen dabei 21 von 24 Instituten die uneingeschränkte Staatsgarantie, wodurch für die Kunden dieser Banken eine vollumfängliche Rückerstattungsgarantie ihrer Einlagen im Konkursfall besteht (vgl. nachfolgende Tabelle 3). Dementgegen haftet der Kanton bei der Waadtländischen und der Berner ${ }^{15}$ Kantonalbank gar nicht und bei der Genfer Kantonalbank nur für gewisse Schuldtitel (Spar- und Vorsorgeguthaben) bis Ende Dezember 2016. ${ }^{16}$ Bei diesen drei Banken greift jedoch davon unabhängig das (allgemein gültige) „Bundesgesetz über die Banken und Sparkassen“: Dieses sichert Vermögenswerte (Guthaben auf Konten, Kassenobligationen) bis zu einer Höhe von CHF 100.000 je Gläubiger ab. ${ }^{17}$ Im Fall der Zwangsliquidation einer Bank wird die Auszahlung der gesicherten Einlage konkret durch die Mitgliedschaft der Bank beim Verein „esisuisse“ gewährleistet.

\section{Verbundstruktur}

Die LB bilden die zweite der drei Ebenen der S-Finanzgruppe, mit den Sparkassen auf der vor- und dem Dachverband DSGV auf der nachgelagerten Stufe. Hingegen operieren die KB nur in einem zwei Ebenen-System mit dem VSKB als übergeordneten Verband. Im deutschen öffentlich-rechtlichen Sektor gibt es ferner Verbände auf regionaler Ebene, die sich primär um die eigenständigen Sparkassen kümmern.

Auffällig ist der Unterschied an rechtlich selbstständigen Unternehmen. So gibt es im deutschen öffentlich-rechtlichen Sektor ein Vielfaches an Partnerunternehmen. Beide Netzwerke haben indes gemein, dass Spezialinstitute aus den Bereichen Leasing, Versicherung, Bausparen, Aus- und Weiterbildung, Vermögensverwaltung, Wertpapiergeschäft sowie IT die geschäftsmodell-spezifische Produktpalette der Banken erweitern. Hierdurch können

15 Die Garantie für die Berner Kantonalbank wurde per 31.12.2012 mit der Übergangsregelung aufgehoben, dass die Staatsgarantie für vor 2006 ausgegebene Anleihen bis zu deren Fälligkeit bestehen bleibt (VSKB 2013).

16 Aufgrund der Spar- und Vorsorgeguthaben im Bestandsgeschäft (bis 2016) wird die Genfer Kantonalbank (noch) mit dem Status „beschränkte Staatsgarantie“ ausgewiesen.

17 Ausgenommen von der Garantie sind Aktien- und Partizipationskapital sowie nachrangige Verbindlichkeiten. 
Skalen- und Verbundvorteile, insbesondere im Backoffice-Bereich, realisiert werden (Schackmann-Fallis/Weiß 2009, 87).

Für beide Systeme ist zum einen die subsidiäre Beziehung ${ }^{18}$, d. h. die Kompetenzabgrenzung, zwischen den Stufen prägend und zum anderen das Regionalitätsprinzip. Gleichwohl unterliegen die LB trotz regionaler Verwurzelung im Gegensatz zu den Sparkassen und KB keiner (quasi-)gesetzlich bindenden geografischen Begrenzung (vgl. Brämer et al. 2010c). Ein besonderes Merkmal innerhalb der S-Finanzgruppe ist der zuvor inhaltlich erläuterte Haftungsverbund: eine Einrichtung, die in der Art ist bei den KB nicht vorzufinden ist.

Die nachfolgende Tabelle 4 fasst die im Kapitel II geführte Aufarbeitung der zentralen Charakteristika und Rahmenbedingungen beider Bankengruppen abschließend nochmals zusammen.

Tabelle 4: Sparkassen-Finanzgruppe und das Netzwerk der Kantonalbanken (2014)

\begin{tabular}{|c|c|c|}
\hline & Sparkassen-Finanzgruppe & Netzwerk der Kantonalbanken \\
\hline Anzahl Unternehmen & ca. 600 & ca. 44 \\
\hline Regionalitätsprinzip & ja & ja \\
\hline \multirow{2}{*}{$\begin{array}{ll}\text { Subsidiaritäts- } & \text { i. e. S. } \\
\text { prinzip } & \text { i. w. S. }\end{array}$} & ja & Nein \\
\hline & ja & $\mathrm{Ja}$ \\
\hline Aufbau & dreistufig & zweistufig \\
\hline \multirow[t]{2}{*}{ Verbände } & DSGV & VSKB \\
\hline & 12 Regionale SV & \\
\hline Haftungsverbund & ja & Nein \\
\hline Staatsgarantie & nein & ja \\
\hline
\end{tabular}

III. Einordnung der Geschäftsmodelle

Die vorangestellte Aufarbeitung macht deutlich, dass die acht Landesbanken trotz Ihres Status als eigenständige Konzerne mit teilweise unterschiedlichen Rechtsformen aufgrund Ihrer Einbindung in die S-Finanzgruppe zentrale Gemeinsamkeiten aufweisen. So werden sie allesamt überwiegend von den regionalen Sparkassen- und Giroverbänden im jeweiligen Bundesland getragen. Ihr am Gemeinwohl orientiertes (öffentliches) Aufgabenspektrum ist über die Institute gemeinhin ähnlich gelagert und verbindlich. Zudem bilden Sie gemeinsam die zweite Säule der Verbundstruktur des DSGV und arbeiten so durchweg in einer subsidiären Beziehung mit den regionalen Sparkassen zusammen. Letztlich verlangt auch die gemeinsame Sicherungsreserve der Landesbanken im Grundsatz (annähernd) gleichgelagerte Geschäftsaktivitäten.

Zweitens zeigen sich hinsichtlich der obigen Kriterien erhebliche Parallelen zu und zwischen den schweizerischen Kantonalbanken. Auch Sie befinden sich (mehrheitlich) in öffentlicher Trägerschaft, sind dem gemeinwohlorientierten sogenannten „Leistungsauftrag“

18 Generell fallen alle Geschäfte der Primärebene zu. Erst wenn die Sparkassen aus juristischen bzw. ökonomischen Gründen nicht mehr in der Lage sind, bestimmte Aufgaben zu erfüllen, kommen die LB (Subsidiarität im engeren bzw. weiteren Sinne) zum Einsatz (Brämer et al. 2010b, 202). 
verpflichtet und firmieren als Teil einer Verbundstruktur. Ferner operieren Sie ebenso wie die Landesbanken in einem Umfeld zunehmender Marktkonsolidierung.

Vor diesem Hintergrund stellt die nachfolgende Abgrenzung/Einordnung der Geschäftsmodelle nicht auf einen eins-zu-eins Vergleich der acht Landesbanken mit den 24 Kantonalbanken ab, da dies zu übermäßig kleinteiligen Ergebnissen führen würde (168 Paar-Vergleiche). Mit Blick auf die Zielstellung, einen grundlegenden methodischen Beitrag zur Identifizierung, Klassifizierung und Performancebeurteilung des Geschäftsmodells der Landesbanken im Kontext des Abgleichs mit den Schweizer Instituten zu leisten, erscheint vielmehr ein Sektor-Sektor-Vergleich zweckmäßig. Dass der analytische Nutzen dieser Aggregation den informativen Schaden überwiegt, legen ferner die zuvor konstatierten zentralen Gemeinsamkeiten nahe. ${ }^{19}$

Die Autoren gewichten vor dem Hintergrund der Ausrichtung des Beitrages an dieser Stelle die Interpretierbarkeit der Ergebnisse (auch auf der nachgelagerten Analysestufe) stärker als einen möglichst hohen Detailierungsgrad als Resultat einzelner Institutsvergleiche. Gleichwohl aber geht mit der vorgenommenen (gewichteten) Aggregation ein Informationsverlust einher, welcher durchaus Ausgangspunkt weiterer Studien sein sollte.

\section{Deskriptiv-statistisch}

Zur Einordnung der Geschäftsmodelle überwiegen kennzahlenorientierte Ansätze, wobei der Bilanzstruktur regelmässig eine erhebliche Bedeutung zukommt (Köbler 2015), ist sie doch letztlich Ausdruck geschäftspolitischer Entscheidungen. Tabelle 5 weist die im Schrifttum dominierenden Grössen ${ }^{20}$ sowie weitere ausgewählte Indikatoren entsprechend aus. Dabei stellen die Bilanzsummen jeweils das Aggregat der Aktiva aller LB bzw. aller KB zum jeweiligen Jahresende dar. Im Einklang hierzu liegt allen prozentualen Grössen ${ }^{21}$ jeweils eine gewichtete Durchschnittsbildung auf Basis der individuellen Bilanzsummen der LB bzw. aller KB zum jeweiligen Jahresende zugrunde.

19 Gleichwohl bleibt es unbenommen, dass auf Einzelinstitutsebene mit an Sicherheit grenzender Wahrscheinlichkeit einzelne Geschäftsfelder stärker oder schwächer bearbeitet werden als im gewichteten arithmetischen Mittel.

20 Vgl. Noack (2009); Schrooten (2009a); Brämer et al. (2010a); Blundell-Wignall/Roulet (2013); Beck et al. (2013), Johnes et al. (2014); Brämer (2015); Ayadi et al (2017).

21 Jeweils in von Hundert der aggregierten Bilanzsumme zum Jahresendzeitpunkt. 
Tabelle 5: Indikatoren der Geschäftstätigkeit: Landes- versus Kantonalbanken

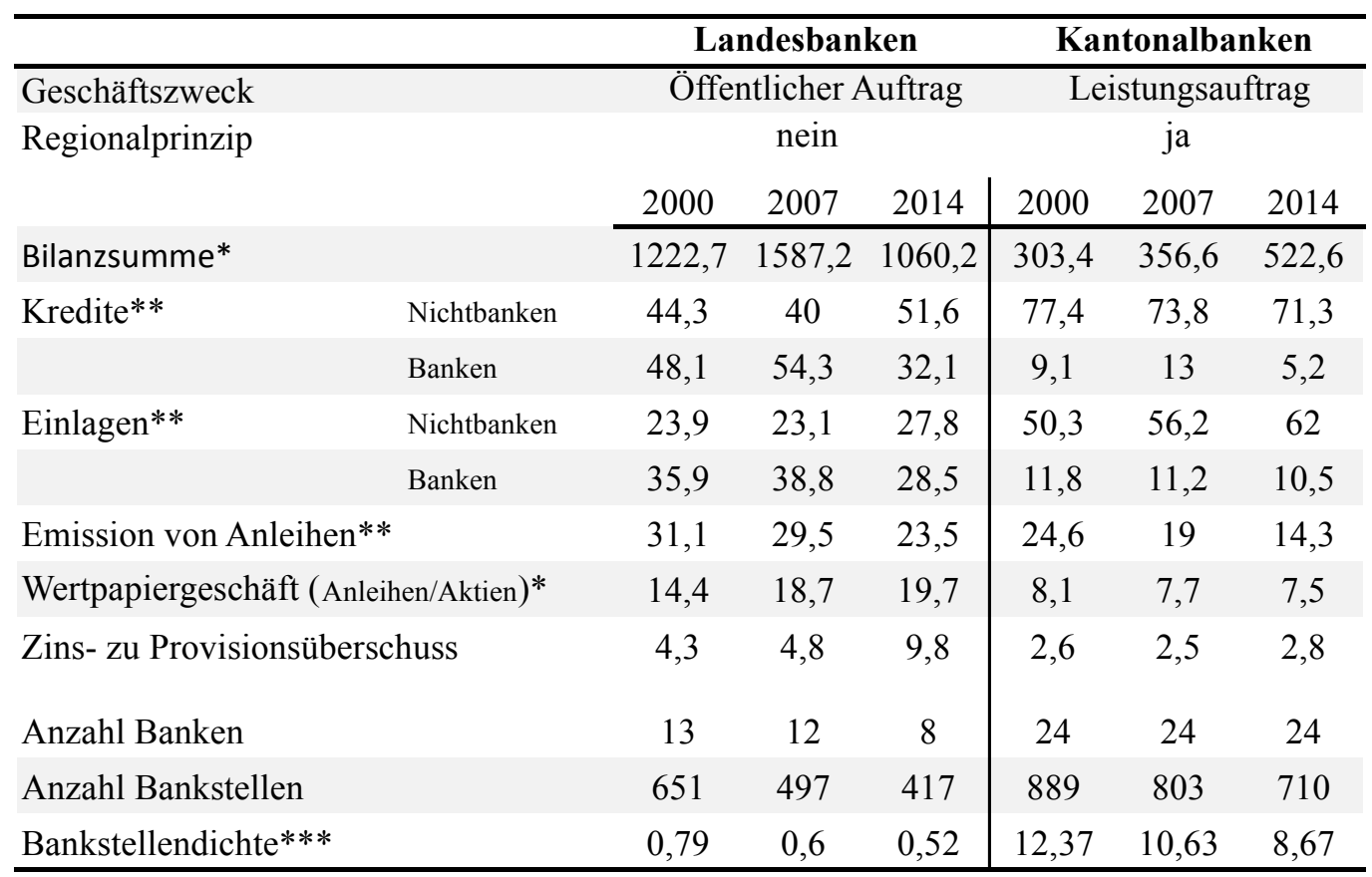

Quelle: Deutsche Bundesbank, Schweizer Nationalbank, Weltbank

Hinweise: *in Mrd €/Mrd CHF, * in v. H. der BS, ** je 100.000 Einwohner

\section{a) Bilanzsumme}

Während die Kantonalbanken in den 15 Jahren stets positive und in Relation zum heimischen Gesamtmarkt überdurchschnittliche Wachstumsraten verzeichneten, kam es bei den LB seit 2007 zu einer substantiellen Bilanzverkürzung. Die Gründe hierfür liegen u. a. in der Zerschlagung einzelner Institute, dem erheblichen Einbruch des Zwischenbankverkehrs, aber auch in den regulatorischen Eigenkapitalanforderungen. Da Sparkassen und Verbände als Eigentümer die LB nur zögerlich mit zusätzlichen Mitteln ausstatten und die anhaltende Ertragsschwäche zudem nur eine begrenzte Thesaurierung von Gewinnen zulässt, ist die Reduzierung der Bilanzsummen die notwendige Konsequenz (Deutsche Bundesbank 2015, 56).

\section{b) Kredit- und Einlagengeschäft}

In deutlicher Abgrenzung zu ihren deutschen Pendants dominiert das Einlagen- und Kreditgeschäft mit privaten Haushalten und Unternehmen bei den KB. Im gesamten Zeitraum lag der Anteil dieser Kredite über $70 \%$ und bildet damit die grösste Aktivposition. Davon wiederum stellten Hypothekarforderungen ${ }^{22}$ mit stets über $60 \%$ den zentralen Part. Bei den LB nehmen die Forderungen an Nichtbanken (Kredite) einen wesentlich geringeren

22 Hypothekarforderungen umfassen grundpfandgesicherte Forderungen auf Wohn-, Büro- und Geschäftshäuser sowie gewerbliche und industrielle Objekte. 
Anteil ein, wenngleich jüngst eine Trendwende erkennbar wird. So verringerte sich bis zum Einsetzen der internationalen Finanzkrise in 2007 der Anteil der Kredite systematisch auf ca. $40 \%$, wuchs aber anschliessend bis auf $51 \%$ in 2014 wieder an. Dabei engagieren sich die LB verstärkt in Flugzeug-, Schiffs- bzw. Transport- und Immobilienfinanzierungen und sind damit neben den deutschen Grossbanken ein zentraler Akteur im gewerblichen Grosskundengeschäft. Spiegelbildlich erfolgte auch die Refinanzierung der KB merklich stärker (ca. $62 \%$ in 2014) - und in der Tendenz zunehmend - über Kundeneinlagen als bei den LB (ca. $28 \%$ in 2014).

Erhebliche Unterschiede zeigen sich auch im Zwischenbankbereich. Kommt diesem für die schweizerischen Institute - aktiv- wie passivseitig - eine nachrangige Bedeutung zu, ist es für die LB aufgrund ihrer Zentralbankfunktion für die Sparkassen von hoher Wichtigkeit. Gleichwohl reduzierten sich die Ausleihungen an andere Geldhäuser von 54,3\% in 2007 auf 32,1\% in 2014. Im gleichen Zeitraum gingen die Einlagen von 38,8 \% auf $28,5 \%$ zurück. Die gesunkene Bedeutung des Interbankengeschäfts ist einerseits Ausdruck des Vertrauensverlustes unter den Instituten, andererseits ein Indiz für die rückläufige Bedeutung der LB als Zentralbanken.

\section{c) Emission von Anleihen}

Historisch bedingt refinanzieren sich die LB - wenngleich rückläufig - substantiell durch die Emission von Inhaberschuldverschreibungen (2000/2007/2014: 31,1 \%/29,5 \%/ $23,5 \%)$. So bestand in der Vergangenheit nur für öffentlich-rechtliche Grundkreditanstalten das Pfandbriefprivileg (Noack 2009, 6). Die Emission an Rentenpapieren ist auch für die KB bedeutsam (2000/2007/2014: 24,6 \%/19,0 \%/14,3 \%). Speziell nach Ausbruch der Finanzkrise 2007 gingen die Emissionen aufgrund von erhöhten Risikoprämien und gestiegener Unsicherheit dennoch zurück. Ein weiterer Faktor ist, dass auch zunehmend große Sparkassen (z. B. Taunus-Sparkasse, Stadtsparkasse Wuppertal) substantielle Volumina an Pfandbriefen zur eigenen Refinanzierung am Markt platzieren und so verstärkt in Konkurrenz zu den LB treten (vgl. Auerbach/Schiereck 2013, S. 90)

\section{d) Wertpapiergeschäft}

Neben den zinstragenden Aktiva umfassen die Bilanzen der LB in substantiellen Umfang zu Handelszwecken gehaltene Wertpapiere (Ø 19,7 \% in 2014). Die Höhe des Handelsgeschäftes „[...] drückt das schwerpunktmäßige Vorhandensein von Investitionsaktivitäten aus, die Markt- und Liquiditätsrisiken ausgesetzt sind" (Ayadi/De Groen 2014, 12). Dabei wurden die Übergangsfristen der Staatsgarantien aufgrund der noch günstigeren Refinanzierungsbedingungen zur übermässigen Fremdkapitalbeschaffung von den deutschen Geldhäusern genutzt. Die passivseitig vorhandenen Volumina überstiegen die für das traditionelle Aktivgeschäft erforderlichen z. T. erheblich. Die Folge war eine regelrechte Flucht der LB in die internationalen Kapitalmärkte verbunden mit risikoreichen Geschäften (Deutsche Bundesbank 2015). Dabei zeigt sich, dass - bis auf die SaarLB - die LB stets wesentlich höhere Handelsbestände in ihren Bilanzen verbuchten als die KB, wenngleich sich die Institute durchaus heterogen verhalten (Abbildung 1).

Für 2014 weist die LBBW $(28,6 \%)$ gefolgt von der Helaba $(17,4 \%)$ die grössten und die BremerLB (1,0\%) gefolgt von der SaarLB $(2,9 \%)$ die niedrigsten Handelsaktiva relativ zur Bilanzsumme auf. Die übrigen Konzerne bewegen sich zwischen 7,2 \% (Nord/LB) 
und 10,4\% (BayernLB). Unterschiede sind auch im Zeitverlauf erkennbar. So weiteten die LBBW und geringfügig die Nord/LB und SaarLB das Handelsgeschäft im Vergleich zu 2007 aus, wohingegen die BayernLB, die HSH Nordbank sowie die LBB Rückgänge verzeichneten.

Abbildung 1: Anteil der Handelsaktiva an der Bilanzsumme der Landesbanken

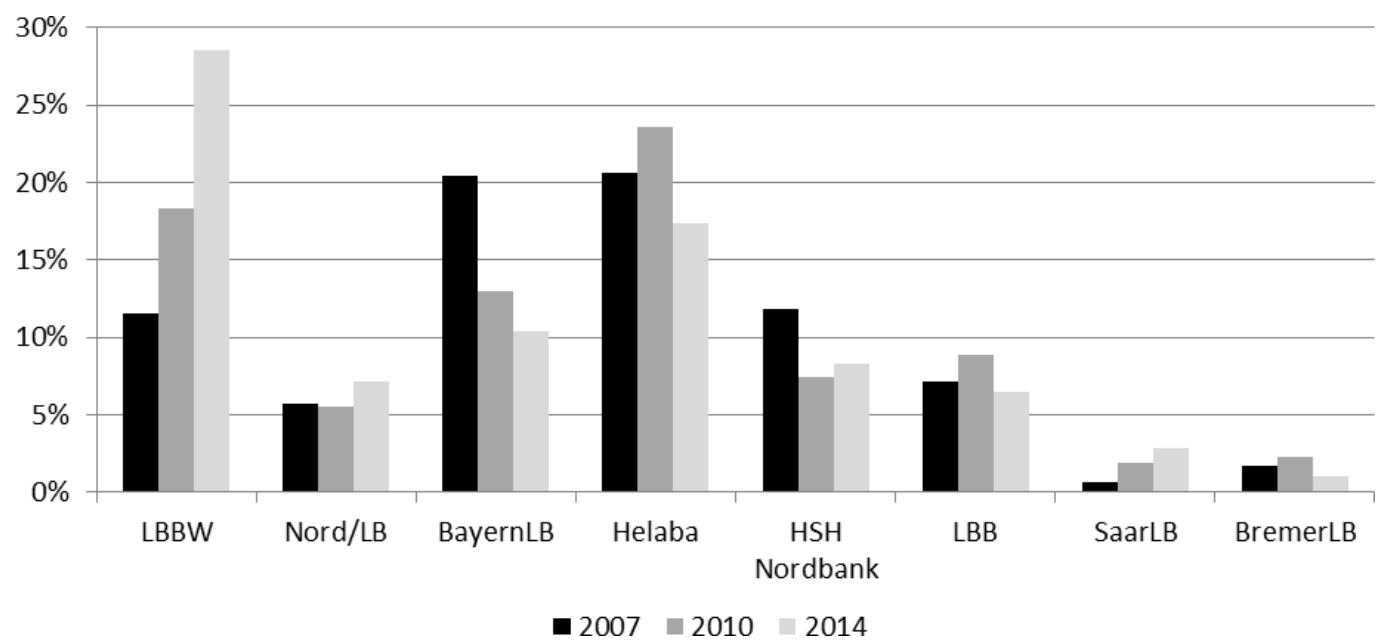

Quelle: Geschäftsberichte, eigene Berechnungen

\section{e) Zins- zu Provisionsüberschuss}

Während der Zinsüberschuss das Ergebnis der Intermediationstätigkeit im engeren Sinne ${ }^{23}$ widerspiegelt, kann der Provisionsüberschuss als das Resultat der Finanzintermediation im weiteren Sinne interpretiert werden. Dieser umfasst die Rückflüsse aus Dienstleistungen (Entgelte) zwischen Kapitalnehmern und -gebern, insbesondere aus dem Wertpapier- und Depotgeschäft. Als das Resultat der strategischen Entscheidungen einer Bank im jeweiligen Marktumfeld ermöglicht das Verhältnis aus Zins- zu Provisionsüberschuss so eine Einordnung des geschäftspolitischen Fokus (vgl. Roengpitya 2014, 60).

Bei den KB ist die nahezu konstante Relation von Zins- zu Provisionsüberschuss (ca. das 3-fache) spiegelbildlicher Ausdruck ihres seit jeher vorrangigen Engagements im Depositen- und Hypothekargeschäft (vgl. Abbildung 2).

23 Unter der Intermediationsleistung im engeren Sinne ist das klassische Bankgeschäft zu verstehen, also die Aufnahme von Einlagen passivseitig und Vergabe von Krediten aktivseitig (Hartmann-Wendels et al. 2014, 2f.). 
Abbildung 2: Zins- zu Provisionsüberschuss beider Bankengruppen

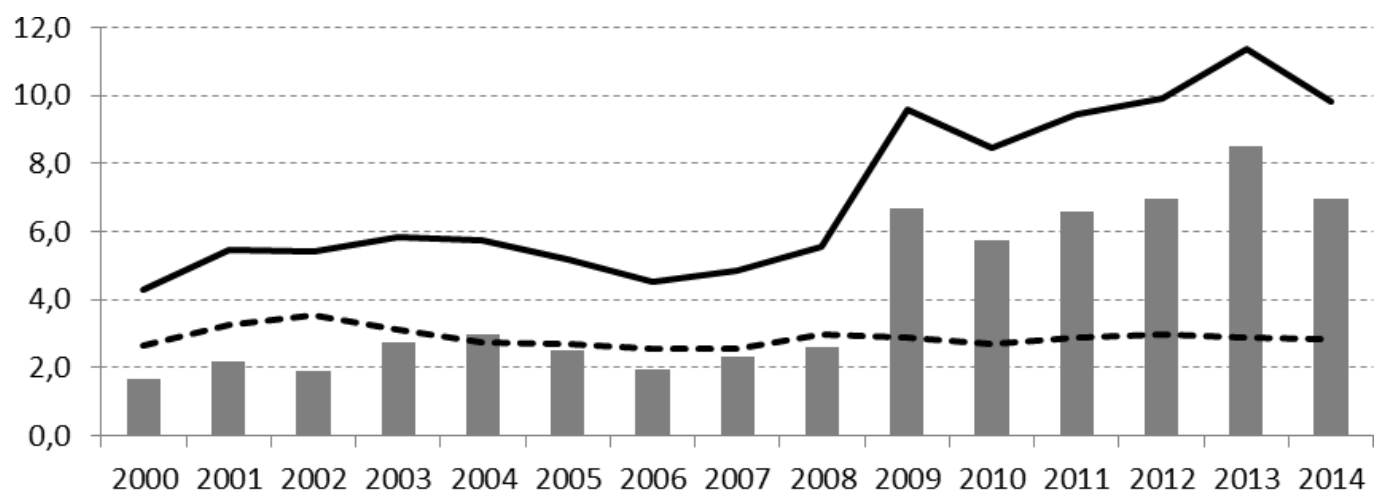

Spread: Landes- und Kantonalbanken —Landesbanken - - - Kantonalbanken

Quelle: Deutsche Bundesbank, Schweizer Nationalbank, eigene Berechnungen

Dementgegen lässt der Verlauf bei den LB faktisch einen Strukturbruch erkennen. Während das Verhältnis aus Zins- zu Provisionsüberschuss zwischen den Jahren 2000 und 2007 nahezu konstant war, verdoppelte es sich im Nachgang bis 2014 (von 4,8 auf 9,8). Im Wesentlichen getrieben wurde diese Entwicklung durch einen Rückgang der Provisionserträge (zw. 2007 bis 2014) um mehr als $63 \%$. Offensichtlich fällt es den LB in diesem volatilen Geschäftsfeld schwer, trotz ihres merklichen quantitativen Ausbaus des Investment Bankings (Schrooten 2009b, 20; Deutsche Bundesbank 2015, 44) dauerhaft substantielle Provisionsüberhänge zu generieren. Vielmehr erwies sich der klassische Ertrag als nachhaltiger Ertragsanker.

Mittelbar schlägt sich diese unterschiedliche Gewichtung der Geschäftsfelder bei den LB und KB im direkten Vergleich der gruppenspezifischen Relationen nieder. So stieg der entsprechende Spread zwischen LB und KB von ursprünglich 1,7 im Jahr 2000 auf 7,0 in 2014.

\section{f) Räumliche Marktpositionierung}

Neben den diskutierten Indikatoren ist vor allem die geografische Orientierung der Banken ein wesentliches Element eines langfristig stabilen Geschäftsmodells (ZEW 2012, 7). So ist das Geschäftsmodell der KB charakterisiert durch inlandsorientiertes Geschäft verbunden mit einer klaren Ausrichtung auf die jeweilige Region - den Kanton (Hess 2008, 974). Auch wenn eine Geschäftsausweitung auf andere Kantone nicht gesetzlich ausgeschlossen ist, gibt es dahingehend eine gegenseitige Übereinkunft, aus welcher hervorgeht, dass sich jede Bank in ihren Geschäftsaktivitäten auf den jeweiligen „Heimatkanton“ fokussiert (Hoffmann/Morkoetter 2011, 146). Eine solche strikte geografische Begrenzung des Geschäftsgebietes fehlt den meisten Landesbanken (Noack 2009, 15). ${ }^{24}$ So findet sich

24 Als Ausnahme ist das Geschäftsgebiet der BremerLB laut $\mathbb{} 2$ der Satzung, i. d. F. vom 1.5.2013 auf Bremen und Niedersachsen beschränkt. In Art. 2 Abs. 1 Satz 2 BayLaG wird der BayernLB ebenfalls eine regionale Restriktion auferlegt, wenngleich zum Geschäftsgebiet dieser Bank, neben Bayern und Deutschland, „[...] die angrenzenden Wirtschaftsräume Europas [...]“ zählen. 
in Satzungen und LB-Gesetzen oftmals die Erlaubnis, im Ausland Niederlassungen zu unterhalten. 25

Hand in Hand hiermit ist ebenso das Filialnetz (je 100.000 Einwohner) der KB um ein Vielfaches breiter als bei den Landesbanken - trotz rückläufiger Tendenz. Die stärkere Reduzierung der Bankstellen bei den LB liegt u. a. in der Zerschlagung der WestLB im Jahre 2012 und der Verschmelzung der SachsenLB mit der LBBW im Jahre 2008 begründet.

\section{Referenzwert-gestütztes Clusterverfahren}

Zwar können die zuvor diskutierten Kennzahlen Basisinformationen über die betrieblichen Strukturen und Prozesse im Unternehmen abbilden, gleichwohl birgt die Aggregation von Detailinformationen stets die Gefahr, die wahren Kausalzusammenhänge der beobachteten Ausprägungen fehlzuinterpretieren (Ewert/Wagenhofer 2008, 521ff.). Einfache Masse gelangen zudem an ihre interpretatorischen Grenzen, wenn sie nicht um wissenschaftlich fundierte Referenzwerte/-intervalle zielkongruent ergänzt werden. Um der Komplexität von Banken als Multiproduktunternehmen gerecht zu werden, können einzelne Grössen empirisch-induktiv in Form eines Kennzahlensystem miteinander verbunden und so ihre Aussagekraft bei der Einordnung des Geschäftsmodells in seiner Gesamtheit deutlich erhöht werden (Greiling 2007, 105f.).

\section{a) Methodischer Ansatz und Datenbasis}

Als eins-zu-eins Grundlage zur Klassifizierung und Einordnung der Geschäftsmodelle von Landes- und Kantonalbanken wird ein solches Verfahren genutzt. Um dabei den gegenwärtigen Stand der Forschung möglichst umfassend aufzunehmen und zugleich die Validität der Ergebnisse zu erhöhen, folgt die vorgenommene Einordnungsmethodik zum einen Ayadi/De Groen (2014) und zum anderen zusätzlich auch Roengpitya et al. (2014). Beide innovativen Ansätze weisen in technischer Hinsicht große Gemeinsamkeiten auf, unterschieden sich jedoch merklich insbesondere in der Auswahl der gewählten Einordungskriterien.

\section{- Auswahl der Input-Variablen}

Die theorie- und praxisgestützte Auswahl der aktiv- und passivseitigen Vergleichskriterien erfolgt unter der Annahme, dass Banken ihre Bilanzstruktur in Abhängigkeit ihres strategischen Engagements in den verschiedenen Intermediationsgeschäften gestalten (Ayadi/De Groen (2014, S. 13)). In Analogie zu Roengpitya et al. (2014) bzw. Ayadi/De Groen (2014) werden daher acht bzw. sieben Input-Variablen zur geschäftsmodellspezifischen Einordnung herangezogen. Alle Kenngrößen werden derweil als Anteil an der Bilanzsumme ausgewiesen (vgl. Tabelle 6).

\section{- Klassifizierungsalgorithmus}

Basierend auf der Arbeit von Ward (1963) nutzen Roengpitya et al. (2014) sowie Ayadi/De Groen (2014) eine hierarchische Klassifizierungsmethode. Dabei werden ausgehend von Einzelbeobachtungen (Bank/Jahr-Paare) schrittweise Gruppen (Cluster) durch

25 Vgl. bspw. $\mathbb{} 2$ Abs. 1 Satzung der Helaba (2012) oder $\$ 2$ Abs. 2 Satzung der HSH Nordbank (2014). 
Zusammenlegung der einander am nächsten liegenden Beobachtungen gebildet. ${ }^{26}$ Auf Basis von Distanz- / Unähnlichkeitsmassen werden dazu die Ähnlichkeiten von jeglichen zwei Beobachtungen in jeder Gruppe sowie die Differenzen unter den Gruppen maximiert. Rein technisch gilt es daher einen guten Kompromiss zwischen der Homogenität innerhalb jeder Gruppe einerseits und der (sinnvoll interpretierbaren) Anzahl an Gruppen andererseits zu finden. Zur Entscheidungsfindung wird der Pseudo-F-Index nach Calinski/Harabasz (1974) herangezogen, welcher die Kompaktheit (i. S. einer kleinen Anzahl an Clustern) gegen die Möglichkeit zur weiteren Differenzierung abwägt. ${ }^{27}$

\section{- Geschäftsmodell-Typen}

Roengpitya et al. (2014) unterteilen auf dieser Basis drei verschiedene GeschäftsmodellTypen:

(1) „Kundeneinlagen refinanzierte Geschäftsbank“

Prägendes Merkmal von Geschäftsbanken mit Spezialisierung auf das Einlagengeschäft sind der hohe Bilanzanteil an Krediten und die starke Abhängigkeit von stabilen Refinanzierungsquellen. Dabei machen die Kundeneinlagen rund zwei Drittel der gesamten Verbindlichkeiten der durchschnittlichen Bank dieser Gruppe aus.

(2) "Interbank- oder Kapitalmarkt refinanzierte Geschäftsbank“

Die repräsentative Bank dieser Gruppe weist aktivseitig ein ähnliches Profil auf wie die Geschäftsbanken mit Spezialsierung auf das Einlagengeschäft. Gänzlich anders verhält es sich hinsichtlich des Refinanzierungsmix. Die Banken dieses Clusters weisen einen substantiell höheren Anteil an Kapitalmarktrefinanzierungen auf.

(3) „kapitalmarktorientierte Bank"

Eine deutlich stärkere Kapitalmarktorientierung weisen die Banken der dritten Kategorie auf. Diese halten (mindestens) die Hälfte ihrer Aktiva in Form von handelbaren Wertpapieren. Zugleich refinanzieren sie sich vorwiegend an Märkten. Die durchschnittliche Bank dieser Gruppe ist am aktivsten im Interbankmarkt tätig. Die entsprechenden Aktiva und Passiva mit ca. einem Fünftel der Bilanzsumme unterstreichen die Spezialisierung auf das Kapialmarktgeschäft..

In ähnlicher Weise unterteilen Ayadi/De Groen (2014) vier alternative GeschäftsmodellTypen:

Tabelle 6: Typenabgrenzung der Geschäftsmodelle

\begin{tabular}{|l|l|}
\hline Ayadi/De Groen (2014) & \multicolumn{1}{|c|}{ Roengpitya et al. (2014) } \\
\cline { 1 - 2 } (1a) Retailgeschäft diversifiziert & (1) $\begin{array}{l}\text { Kundeneinlagen refinanzierte Geschäfts- } \\
\text { bank }\end{array}$ \\
\cline { 1 - 2 } (1b) Retailgeschäft fokussiert & (2) $\begin{array}{l}\text { Interbank- oder Kapitalmarkt } \\
\text { refinanzierte Geschäftsbank }\end{array}$ \\
\hline (2) Interbank-/Kapitalmarkt refinanziert & (3) kapitalmarktorientierte Bank \\
\hline (3) Investmentbankgeschäft &
\end{tabular}

26 Der Clusterbildung bei Roengpitya et al. (2014) liegt eine Kohorte von 222 internationalen Geschäftsbanken zugrunde und bei Ayadi/De Groen (2014) von 147 europäischen Geschäftsbanken zw. 2005 bis 2013).

27 Der F-Index ist artverwand zu den Informationskriterien von Akaike und Schwarz, welche regelmäßig zur Ermittlung der optimalen Lag-Anzahl bei Zeitreihen-Regressionen herangezogen werden. 
In einem zweiten Schritt werden den verfahrensendogen identifizierten GeschäftsmodellClustern Referenzwerte in Form des arithmetischen Mittels eines jeden Vergleichskriteriums zugeordnet. Als Charakteristikum fungieren diese Referenzwerte als Benchmark zur geschäftsmodellspezifischen Einordnung anderer Banken außerhalb der zugrundegelegten Kohorten.

Den methodischen Aufriss fasst Tabelle 7 zusammen, wobei die fett gedruckten Merkmale aus Sicht der (jeweiligen) Autoren die zentralen zur Einordnung der Geschäftsmodelle darstellen.

Tabelle 7: Geschäftsmodelle nach Roengpitya et al. (2014) / Ayadi/De Groen (2014)

Roengpitya et al. (2014)

Durchschnittswerte in v. H.

der Bilanzsumme

(ohne Derivate)

Interbank-/ Kapital- Kapitalmarkt-

Kredite (,gross loans')

Retailgeschäft markt refinanziert geschäft

Handel $^{28}$

62,2

65,2

25,5

Handelsbuch ${ }^{29}$

22,4

20,7

51,2

Forderungen an Banken

5,1

7,1

17,3

Einlagen von Banken

8,5

8,2

21,8

7,8

13,8

19,1

Wholesale-Verbindlichkeiten ${ }^{30}$

10,8

36,7

18,2

Stabile Refinanzierung ${ }^{31}$

73,8

63,1

48,6

Einlagen

66,7

35,6

38,0

\section{Ayadi/De Groen (2014)}

\begin{tabular}{lcccc}
\hline $\begin{array}{l}\text { Durchschnittswerte in v. H. } \\
\text { der Bilanzsumme }\end{array}$ & $\begin{array}{c}\text { Retailgeschäft } \\
\text { fokussiert }\end{array}$ & $\begin{array}{c}\text { Retailgeschäft } \\
\text { diversifiziert }\end{array}$ & $\begin{array}{c}\text { Interbank-/ } \\
\text { Kapitalmarkt } \\
\text { refinanziert }\end{array}$ & $\begin{array}{c}\text { Investment- } \\
\text { bank }\end{array}$ \\
\hline Forderungen an Kunden & 60,8 & 67,5 & 31,4 & 37,4 \\
Handelsaktiva ${ }^{21}$ & 27,9 & 23,3 & 28,1 & 51,2 \\
Forderungen an Banken & 7,4 & 6,2 & 38,4 & 9,5 \\
Einlagen von Banken & 13,1 & 8,5 & 37,4 & 14,3 \\
Einlagen von Kunden & 62,8 & 34,2 & 19,1 & 23,1 \\
Verbindlichkeiten ${ }^{32}$ & 14,3 & 48,0 & 32,6 & 44,8 \\
Derivate & 2,8 & 3,4 & 4,5 & 15,2 \\
Eigenkapital (EK) & 5,5 & 4,7 & 5,9 & 3,9 \\
\hline
\end{tabular}

28 Aktiva des Handelsbestandes zuzüglich Verbindlichkeiten, bereinigt um Derivate.

$29 \mathrm{Zu}$ Handelszwecken gehaltene Wertpapiere.

30 Sonstige Einlagen zuzüglich kurzfristiger Kreditaufnahme und langfristiger Refinanzierungen.

31 Kundeneinlagen plus langfristiger Refinanzierungen.

32 As Residuum aus Gesamtschulden weniger Kundeneinlagen, Interbankverbindlichkeiten, EK und Derivate. 


\section{b) Analyseergebnisse}

Die nachfolgende Tabelle 8 weist die ermittelten Resultate für alle Bankengruppen/JahrPaar Kombinationen aus und offenbart zum Teil erhebliche Unterschiede in den Geschäftsmodellen der Landes- im Vergleich zu den Kantonalbanken.

Tabelle 8: Geschäftsmodelle der Landes- und Kantonalbanken (für 2000, 2007 und 2014)

\begin{tabular}{|c|c|c|c|c|c|c|c|c|c|c|}
\hline & & & Method & lische Grund & llage: Roeng & gpitya et & al. (2014) & & & \\
\hline & Retail & geschäft & $\begin{array}{l}\text { Interbank-/ } \\
\text { Kapitalmarkt } \\
\text { refinanziert }\end{array}$ & $\begin{array}{l}\text { Kapitalmarkt- } \\
\text { geschäft }\end{array}$ & \begin{tabular}{|c|} 
Aggregierte \\
Abweichung \\
zu Referenz- \\
werten \\
\end{tabular} & Reta & ilgeschäft & $\begin{array}{c}\text { Interbank-/ } \\
\text { Kapitalmarkt } \\
\text { refinanziert }\end{array}$ & $\begin{array}{c}\text { Kapitalmarkt } \\
\text { geschäft }\end{array}$ & \\
\hline & & & & & 2000 & & & & & \\
\hline & & 70 & 45 & 52 & absolut & & 34 & 25 & 67 & \\
\hline & & 685 & 930 & 910 & quadriert & & 467 & 274 & 2800 & \\
\hline & & & & & 2007 & & & & & \\
\hline & & 75 & 54 & 49 & absolut & & 25 & 28 & 58 & \\
\hline & & 944 & 1274 & 818 & quadriert & & 236 & 348 & 2396 & \\
\hline & & & & & 2014 & & & & & \\
\hline ฮี & & 50 & 33 & 55 & absolut & & 17 & 31 & 58 & \\
\hline 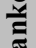 & & 994 & 424 & 1229 & quadriert & & 123 & 490 & 2228 & \\
\hline$\pi$ & & & Method & dische Grun & dlage: Ayadi & i/De Gro & en (2014) & & & \\
\hline हूँ & Retail & geschäft & Interbank-/ & & \begin{tabular}{|l|} 
Aggregierte \\
\end{tabular} & Retai & ilgeschäft & Interbank-/ & $t$ & \\
\hline 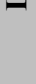 & fokussiert & diversifiziert & $\begin{array}{c}\text { Kapitalmarkt } \\
\text { refinanziert }\end{array}$ & bank & $\begin{array}{c}\text { zu Referenz- } \\
\text { werten }\end{array}$ & fokussiert & $t$ diversifiziert & $\begin{array}{l}\text { Kapitalmarkt } \\
\text { refinanziert }\end{array}$ & bank & \\
\hline & & & & & 2000 & & & & & \\
\hline & 138 & 100 & 34 & 106 & absolut & 55 & 52 & 107 & 84 & \\
\hline & 4367 & 2832 & 323 & 3390 & quadriert & 931 & 711 & 2890 & 2723 & \\
\hline & & & & & 2007 & & & & & \\
\hline & 141 & 108 & 32 & 113 & absolut & 48 & 67 & 114 & 100 & \\
\hline & 4904 & 3571 & 359 & 3777 & quadriert & 674 & 1182 & 3143 & 3293 & \\
\hline & & & & & 2014 & & & & & \\
\hline & 105 & 80 & 35 & 98 & absolut & 34 & 73 & 135 & 115 & \\
\hline & 2512 & 1620 & 243 & 2096 & quadriert & 477 & 1776 & 4329 & 4068 & \\
\hline
\end{tabular}

Quelle: Deutsche Bundesbank, Schweizer Nationalbank, eigene Berechnungen

\section{- Einordnung der Geschäftsmodelle}

Mithin werden zur Einordnung der Landes- und Kantonalbanken nun die absoluten und zur stärkeren Gewichtung grosser Divergenzen die quadrierten Abweichungen (in Prozentpunkten) zu den Referenzwerten von Roengpitya et al. (2014) bzw. Ayadi/De Groen (2014) ermittelt. Anschliessend sind die minimalen Unterschiede zu den alternativen Geschäftsmodellklassifikationen für beide Bankensektoren im Zeitablauf (2000, 2007, 2014) zu identifizieren (vgl. Tabelle 10 -15 im Anhang).

Entsprechend des Ansatzes von Ayadi/De Groen (2014) sind die Landesbanken in jedem der drei Jahre als „Interbank-/Kapitalmarkt refinanzierte Geschäftsbank“ zu klassifizieren. Auch die Anwendung des Modells von Roengpitya et al. (2014) bestätigt für 2014 und 2000 (absolut) die Ausrichtung der Landesbanken auf das aktiv- wie passivseitige 
Zwischenbankgeschäft und das Handelsgeschäft. Für eine Klassifikation als „Kapitalmarktgeschäft"-orientierte Institute verbunden mit einen noch stärken Fokus auf das Investment Banking sprechen dagegen die Resultate für 2000 (quadriert) und 2007. Dies stützt die gemeinhin vermutete Annäherung zu den Grossbanken in diesem Zeitraum (Schrooten 2009b, 20; Deutsche Bundesbank 2015, 44). Ein Grund hierfür liegt in den Übergangsfristen zur Gewährträgerhaftung und der damit verbundenen Flucht in die internationalen Kapitalmärkte nach 2005.

Dementgegen sind die eidgenössischen Institute heute und auch bereits vor Einsetzen der Finanzkrise als „Retailgeschäft diversifiziert“ bzw. „Retailgeschäft fokussierte “ Geschäftsbanken einzugruppieren. Dies bedeutet, dass traditionelle Kundenkredite (im Fall der KB Hypothekarforderungen) aktivseitig das Haupttätigkeitsfeld darstellen. Passivseitig werden vorrangig Kundeneinlagen genutzt und weniger nicht-traditionelle Finanzierungsquellen bzw. der Weg über den Kapitalmarkt (charakteristisch für das diversifizierte Modell). Dabei hat die Konzentration auf Kundendepositen im Vergleich zur Ausgabe von Anleihen (Positionen in der Bilanz: Kassenobligationen, Anleihen und Pfandbriefdarlehen; vgl. dazu Tabelle 5) seit 2000 zugenommen. Das erklärt die Veränderung des Geschäftsmodells von 2000 zu 2007 und 2014 und unterstreicht die heutige Positionierung der KB als Geldhäuser, die sich auf das regional ausgerichtete, klassische Kredit- und Einlagengeschäft konzentrieren.

\section{Analyse der Leistungsfähigkeit ${ }^{33}$}

In Hinblick auf die nachhaltige Tragfähigkeit der zuvor identifizierten Geschäftsmodele schliesst die dezidierte Performanceanalyse den Vergleich beider Bankengruppen ab.

1. Jahresüberschuss

Abbildung 3: Jahresüberschuss vor Steuern von 2000 bis 2014

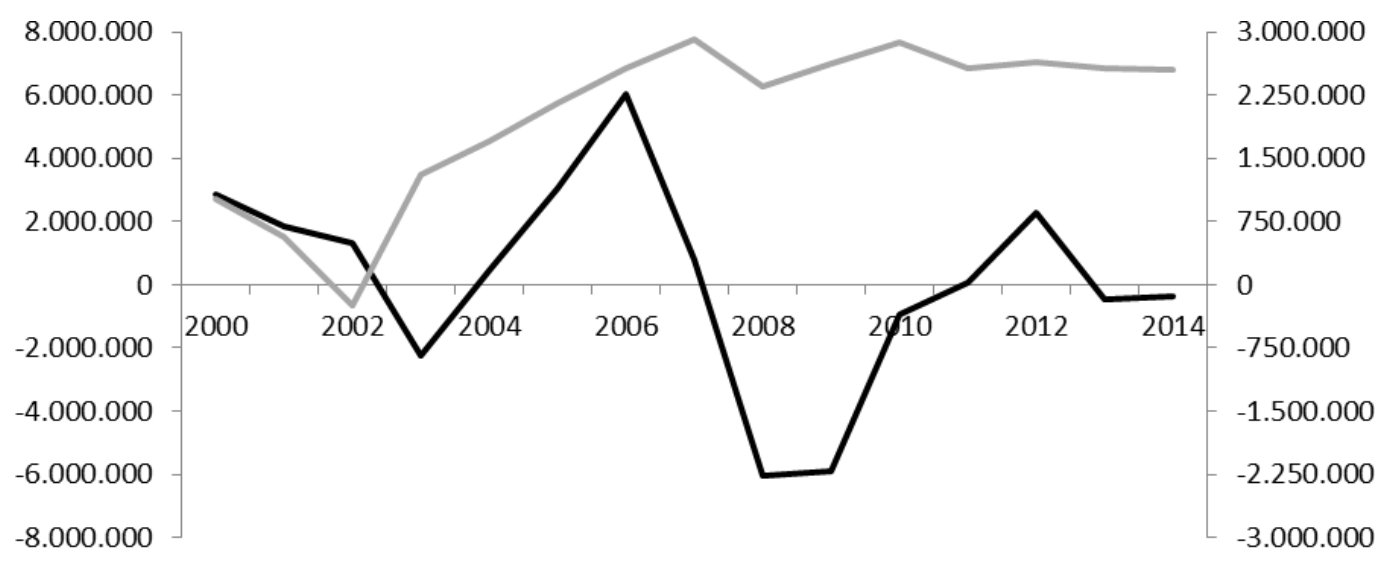

—Landesbanken (Achse links, in Tsd. EUR) — Kantonalbanken (Achse rechts, in Tsd. CHF)

Quelle: Deutsche Bundesbank, Schweizer Nationalbank, eigene Berechnungen

33 Nachfolgende findet stets eine bilanzsummengewichtete Durchschnittsbildung beider Bankengruppen statt. 
Abbildung 3 offenbart einen weitgehend stabilen Jahresüberschuss (v. S.) der KB - vor, während und nach der Finanzkrise. Die Verluste im Zuge der Dotcom-Blase im Jahre 2000 könnten derweil auf eine Intensivierung des Kapitalmarktgeschäfts um die Jahrtausendwende (Tabelle 7) zurückzuführen sein. Auch der Gewinn der LB brach in 2000 stark ein. Die in 2007 einsetzende Finanzkrise jedoch hatte weitaus höhere Verluste zur Folge und wirkt bis heute nach.

\section{Rentabilität und Stabilität}

Ein tiefergehendes Bild der langfristigen Erfolgsträchtigkeit alternativer Geschäftsmodele zeichnen zum einen gängige Rentabilitätsgrössen, indem die Erfolgsgrösse ins Verhältnis zum eingesetzten Kapital gesetzt wird, zum anderen in der Wissenschaft etablierte Stabilitätsindikatoren auf die Risikotragfähigkeit beider Bankengruppen schliessen.

a) Rentabilität: Eigen- und Gesamtkapitalrendite ${ }^{34}$

Tabelle 9: Rentabilität und Stabilität der Landes- und Kantonalbanken (2000-2014)

\begin{tabular}{|c|c|c|c|c|c|c|c|c|}
\hline \multirow{3}{*}{ Jahr } & \multicolumn{4}{|c|}{ Rentabilität } & \multicolumn{4}{|c|}{ Stabilität } \\
\hline & \multicolumn{2}{|c|}{ Eigenkapitalrendite } & \multicolumn{2}{|c|}{ Gesamtkapitalrendite } & \multicolumn{2}{|c|}{ Eigenkapitalquote } & \multicolumn{2}{|c|}{ Z-Score } \\
\hline & $\overline{\mathrm{LB}}$ & KB & $\overline{\mathrm{LB}}$ & KB & $\overline{\text { LB }}$ & $\overline{\text { KB }}$ & $\overline{L B}$ & $\overline{K B}$ \\
\hline 2000 & $6,1 \%$ & $5,3 \%$ & $6,5 \%$ & $2,7 \%$ & $3,8 \%$ & $6,3 \%$ & 8,4 & 16,5 \\
\hline 2001 & $3,4 \%$ & $2,9 \%$ & $6,3 \%$ & $2,6 \%$ & $4,2 \%$ & $6,3 \%$ & 8,5 & 16,3 \\
\hline 2002 & $2,1 \%$ & $-1,2 \%$ & $5,2 \%$ & $1,8 \%$ & $4,7 \%$ & $6,2 \%$ & 8,0 & 14,7 \\
\hline 2003 & $-3,5 \%$ & $5,9 \%$ & $4,3 \%$ & $1,9 \%$ & $4,7 \%$ & $7,1 \%$ & 7,3 & 16,5 \\
\hline 2004 & $0,9 \%$ & $7,0 \%$ & $4,5 \%$ & $1,8 \%$ & $4,3 \%$ & $7,7 \%$ & 7,1 & 17,4 \\
\hline 2005 & $5,0 \%$ & $8,2 \%$ & $4,9 \%$ & $1,9 \%$ & $4,4 \%$ & $8,1 \%$ & 7,6 & 18,2 \\
\hline 2006 & $9,6 \%$ & $9,1 \%$ & $5,4 \%$ & $2,1 \%$ & $4,4 \%$ & $8,3 \%$ & 7,9 & 18,9 \\
\hline 2007 & $1,2 \%$ & $9,8 \%$ & $5,3 \%$ & $2,4 \%$ & $4,1 \%$ & $8,4 \%$ & 7,6 & 19,8 \\
\hline 2008 & $-9,1 \%$ & $7,8 \%$ & $4,9 \%$ & $2,2 \%$ & $4,3 \%$ & $7,8 \%$ & 7,4 & 18,3 \\
\hline 2009 & $-8,0 \%$ & $8,2 \%$ & $3,0 \%$ & $1,6 \%$ & $5,1 \%$ & $7,9 \%$ & 6,5 & 17,5 \\
\hline 2010 & $-1,4 \%$ & $8,6 \%$ & $2,5 \%$ & $1,5 \%$ & $4,5 \%$ & $7,9 \%$ & 5,7 & 17,2 \\
\hline 2011 & $0,1 \%$ & $7,4 \%$ & $5,0 \%$ & $1,3 \%$ & $4,6 \%$ & $7,7 \%$ & 7,8 & 16,6 \\
\hline 2012 & $3,7 \%$ & $7,3 \%$ & $4,8 \%$ & $1,2 \%$ & $4,9 \%$ & $7,5 \%$ & 7,9 & 15,9 \\
\hline 2013 & $-0,8 \%$ & $6,8 \%$ & $3,1 \%$ & $1,0 \%$ & $5,6 \%$ & $7,6 \%$ & 7,1 & 15,9 \\
\hline 2014 & $-0,6 \%$ & $6,5 \%$ & $2,6 \%$ & $0,9 \%$ & $5,5 \%$ & $7,5 \%$ & 6,6 & 15,5 \\
\hline Mittelwert & $0,6 \%$ & $6,6 \%$ & 4,5\% & $1,8 \%$ & $4,6 \%$ & $7,5 \%$ & $\overline{7,43}$ & 17,02 \\
\hline Median & $0,9 \%$ & $7,3 \%$ & $4,9 \%$ & $1,8 \%$ & $4,5 \%$ & $7,7 \%$ & 7,58 & 16,58 \\
\hline Spread* & $-6,70$ & 1,12 & $-3,85$ & $-1,74$ & 1,68 & 1,22 & $-1,76$ & $-0,96$ \\
\hline Stan.-abw. ${ }^{* *}$ & 4,95 & 2,74 & 1,23 & 0,55 & 0,51 & 0,70 & 0,75 & 1,36 \\
\hline Var.-koef. ${ }^{* \star}$ & $870 \%$ & $41 \%$ & $27 \%$ & $30 \%$ & $11 \%$ & $9 \%$ & $10 \%$ & $8 \%$ \\
\hline
\end{tabular}

Quelle: Deutsche Bundesbank, Schweizer Nationalbank, eigene Berechnungen

Hinweis: * Differenz zwischen 2000 und 2014; ** Angabe in Prozentpunkten

34 Die Eigenkapitalrendite (Return on Equity (RoE)) wurde als Verhältnis aus Jahresüberschuss (v. S.) zum eingesetzten Eigenkapital ermittelt und drückt damit die Verzinsung des bilanziellen Eigenkapitals aus. Hingegen rekurriert Die Gesamtkapitalrendite (Return on Assets (RoA)) auf die Gesamtver- 
Die Eigenkapitalrendite folgt in ihrem Verlauf aufgrund ihrer Abhängigkeit dem Jahresüberschuss (v. S.). Während die KB seit 2004 durchgängig Werte über $6 \%$ aufwiesen, zeigt sich der RoE der LB sehr volatil und zum Teil negativ. Im internationalen Vergleich weisen beide Gruppen unterdurchschnittliche Renditen auf. ${ }^{35}$ Insbesondere nach dem Einsetzen der internationalen Krise in 2007 waren die Renditen für die Eigenkapitalgeber der LB negativ $(-9,08 \%$ in 2008$)$.

Ein anderes Bild legt die Gesamtkapitalverzinsung nahe. So wiesen die LB im gesamten Betrachtungszeitraum höhere Werte auf als die KB. Bei einem mittleren RoA von 1,8\% über den Betrachtungszeitraum nehmen die KB eine unterdurchschnittliche Position beim Vergleich mit anderen Bankensystemen ein (Richter 2013, 183). Mit einem Mittelwert von 4,5\% schneiden die LB damit besser ab bei dennoch merklicher Schwankung um den Mittelwert (Variationskoeffizient bei $27 \%$ ). Der grundsätzliche Verlauf des RoA ist derweil im gesamten europäischen Bankensektor beobachtbar (Richter 2013, 184) und folgt dem gesamtwirtschaftlichen Zinsniveau.

\section{b) Stabilität: Eigenkapitalquote und Z-Score}

Die Eigenkapitalquote (EKQ) als Quotient aus eingesetztem Eigenkapital zur Bilanzsumme (BS) gibt Auskunft über die Finanzierungsstruktur. Je niedriger die EKQ, desto stärker ist ein Geldhaus von externen Gläubigern abhängig. Die Möglichkeit negative externe Schocks mit eigenen Mitteln aufzufangen, ist entsprechend geringer. Tabelle 8 verdeutlicht, dass die schweizerischen Institute stets substantiell mehr Eigenkapital einsetzten als die deutschen. Gleichwohl ist seit 2007 bei den Landesbanken ein kontinuierlicher Zuwachs der EKQ zu beobachten.

Umfassender kann die Risikoabsorptionsfähigkeit einer Bank/Bankengruppe anhand des Z-Scores beurteilt werden (Kühlwein/Burkert 2015, 160). Dieser wertet das jeweilige Geschäftsmodell als umso stabiler, je höher die Eigenkapitalquote (EKQ), respektive die Gesamtkapitalrendite ausfallen. Dementgegen steigt das Insolvenzrisiko mit zunehmender Volatilität der Unternehmensgewinne - gemessen über die Standardabweichung des RoA ( $\sigma$ RoA). Der Z-Score der Bankengruppe $k$ zum Zeitpunkt $t$ wird formal bestimmt als (Schaeck/Čihák 2008, 17):

$$
Z-\operatorname{Score}_{k, t}=\left(E K Q_{k, t}+\operatorname{RoA}_{k, t}\right) / \operatorname{RoA}_{k}
$$

Mit einem durchschnittlichen Z-Score von 17,0 weisen die KB ein niedrigeres Insolvenzrisiko als die LB auf, die im aggregierten Mittel nur einen Wert von 7,4 erreichen. Dazu zeigt sich, dass den kantonalen Banken auch im Vergleich mit dem deutschen $(\varnothing 8,4)$ sowie dem schweizerischen Bankenmarkt $(\varnothing 7,3)$ eine höhere Stabilität attestiert werden muss. Dies steht im Einklang mit den Befunden von Altunbas et al. (2011, 28) und Gischer/Richter (2011, 188f.), die dem klassischen Intermediationsgeschäft eine stabilisierende Wirkung bescheinigen.

zinsung des eingesetzten Kapitals als Verhältnis aus Jahresüberschuss (v. S.) zuzüglich der Fremdkapitalzinsen zum Eigen- und Fremdkapital.

35 Der Sachverständigenrat (2008, 102) weist als Durchschnittswert über die Jahre 2004 bis 2006 beispielhaft für folgende nationalen Bankensysteme aus: Vereinigtes Königreich 18,6 \%; Frankreich 17,2 \%; Spanien 17,7 \%; Italien 13,9 \% und Österreich 15,5\%. Zu vergleichbaren Ergebnissen gelangt ferner Richter $(2013,181)$. 


\section{Wirtschaftlichkeit / Produktivität}

Bei der Bestimmung der Leistungsfähigkeit von Unternehmen im Allgemeinen und Banken im Speziellen sind die Konzepte der Wirtschaftlichkeit versus Produktivität zwar eng miteinander verbunden, aber dennoch präzise voneinander zu trennen.

\section{a) Theoretische Vorüberlegung}

Die Cost-Income-Ratio (CIR) als Prozentzahl drückt aus, wie viel Aufwand nötig ist, um eine Einheit operativen Ertrag zu generieren:

$$
C I R=\frac{\text { Verwaltungsaufwand }}{\text { Operative Erträge }}
$$

Ein Kreditinstitut ist demnach vermeintlich umso leistungsfähiger, je kleiner die CIR ausfällt. Der Verwaltungsaufwand umfasst dabei die Personal- und Sachaufwendungen sowie die Abschreibungen. Die operativen Erträge einer Bank wiederum setzen sich aus dem Zinsüberschuss, dem Provisionsüberschuss, dem Handelsergebnis und dem Saldo der sonstigen Erträge und Aufwendungen zusammen (Varmaz 2006, 308).

Problematisch ist, dass in die CIR preisliche Komponenten einfliessen. Als Wertgrösse wird so die Leistungsfähigkeit im Sinne von Wirtschaftlichkeit abgeleitet. Mitnichten muss diese jedoch die Entwicklung der Produktivität als Mengenkonzept nachzeichnen (Burger/ Moormann 2008, 66). Gischer/Richter (2014) widmen sich den Verzerrungswirkungen der CIR und leiten einen adjustierten Ansatz unter Berücksichtigung des Wettbewerbsgrads und des Lohnniveaus ab.

\section{Bestimmungsgrösse Wettbewerbsgrad}

Unterschiedliche Wettbewerbsverhältnisse können sowohl Soll- als auch Habenzinsen und somit den Zinsüberschuss als Hauptbestandteil der operativen Erträge (Richter 2013, 197f.) beeinflussen. Stehen Kreditinstitute in starker Konkurrenz zueinander, wird die realisierbare Zinsspanne ceteris paribus geringer und damit die CIR höher ausfallen. In einem konkurrenzintensiven Umfeld münden Produktivitätsfortschritte nicht in zusätzlichen Renten für die Banken, sondern vielmehr in besseren Konditionen für die Kunden.

Ein geeignetes wie gängiges Mass, um die individuellen Preissetzungsspielräume einer Bankengruppe $k$ zum Zeitpunkt $t$ qualitativ und quantitativ zu bewerten, ist der LernerIndex $\left(\boldsymbol{L} \boldsymbol{I}_{k, t}\right)$ bzw. der abgeleitete Mark-Up $\left(\boldsymbol{M}_{k, t}\right)$ (Lerner 1934; Koetter 2008, 232f.; Ayadi et al. 2009, 58f.; Arrawatia/Misra 2012, 121). Der Indikator setzt das am Markt erzielte Preisniveau in Beziehung zu den unternehmenseigenen Grenzkosten:

$$
L I_{k, t}=\frac{P(Q)-C_{k, t}^{\prime}(q)}{P(Q)} \text { bzw. } M_{k, t}=\frac{P(Q)}{C_{k, t}^{\prime}(q)}=\frac{1}{1-L I_{k, t}}
$$

Während der Lerner-Index Werte zwischen null und eins annimmt, ist der Mark-Up im Sinne eines Preisaufschlages auf die Grenzkosten zu interpretieren und damit grundsätzlich nach oben unbegrenzt. Beide Grössen fallen umso höher aus, je stärker ein Unternehmen in der Lage ist, einen Preis oberhalb seiner Grenzkosten durchzusetzen (Neumann 2000, 87f.). 


\section{Bestimmungsgrösse Lohnniveau}

Darüber hinaus können unterschiedliche länderspezifische Lohnniveaus über die korrespondierenden Personalkosten die Verwaltungsaufwendungen und somit die CIR-Werte beeinflussen, ohne Ausdruck bestehender Produktivitätsunterschiede zu sein (Burger/ Moormann 2008, 92ff.; Gischer/Richter 2014, 17f.). Entsprechend sind diese gleichermassen bei der Beurteilung und Interpretation der Leistungsfähigkeit einer Bank/Bankengruppe ins Kalkül zu ziehen. ${ }^{36}$

\section{b) Empirische Auswertung - Adjustierte CIR}

Methodisch auf der Arbeit von Gischer/Richter 2014 fussend stellt die nachfolgende Tabelle 9 die Cost-Income-Ratio in ihrer Reinform und in ihrer adjustierten Form dar.

Tabelle 10: Wirtschaftlichkeit / Produktivität der Landes- und Kantonalbanken (2000-2014)

\begin{tabular}{|c|c|c|c|c|c|c|c|c|}
\hline \multirow{3}{*}{ Jahr } & \multirow{2}{*}{\multicolumn{2}{|c|}{$\begin{array}{c}\text { Wettbewerbsgrad } \\
\text { (Mark-up) }\end{array}$}} & \multirow{2}{*}{\multicolumn{2}{|c|}{$\begin{array}{c}\text { Personalkosten (pro } \\
\text { Kopf/ in Tsd Euro) }\end{array}$}} & \multicolumn{4}{|c|}{ Wirtschaftlichkeit / Produktivität } \\
\hline & & & & & \multicolumn{2}{|c|}{ CIR (unbereinigt) } & \multicolumn{2}{|c|}{ CIR (adjustiert) } \\
\hline & LB & KB & LB & KB & LB & KB & LB & $\overline{K B}$ \\
\hline 2000 & 1,09 & 1,46 & 80,4 & 75,5 & $55,9 \%$ & $50,1 \%$ & $55,9 \%$ & $60,7 \%$ \\
\hline 2001 & 1,10 & 1,48 & 84,4 & 83,1 & $57,1 \%$ & $54,8 \%$ & $57,1 \%$ & $66,7 \%$ \\
\hline 2002 & 1,10 & 1,63 & 85,5 & 86,5 & $56,1 \%$ & $54,0 \%$ & $56,1 \%$ & $63,6 \%$ \\
\hline 2003 & 1,14 & 1,81 & 83,4 & 92,0 & $53,1 \%$ & $52,0 \%$ & $53,1 \%$ & $58,8 \%$ \\
\hline 2004 & 1,14 & 1,90 & 86,7 & 93,6 & $53,5 \%$ & $51,2 \%$ & $53,5 \%$ & $57,3 \%$ \\
\hline 2005 & 1,12 & 1,96 & 89,7 & 99,0 & $59,3 \%$ & $48,8 \%$ & $59,3 \%$ & $52,2 \%$ \\
\hline 2006 & 1,10 & 1,88 & 106,4 & 102,0 & $53,6 \%$ & $46,8 \%$ & $53,6 \%$ & $53,6 \%$ \\
\hline 2007 & 1,10 & 1,73 & 94,0 & 103,6 & $61,1 \%$ & $47,8 \%$ & $61,1 \%$ & $50,9 \%$ \\
\hline 2008 & 1,12 & 1,72 & 93,2 & 104,1 & $54,6 \%$ & $52,6 \%$ & $54,6 \%$ & $58,4 \%$ \\
\hline 2009 & 1,18 & 2,12 & 93,5 & 110,5 & $51,0 \%$ & $50,0 \%$ & $51,0 \%$ & $54,0 \%$ \\
\hline 2010 & 1,21 & 2,28 & 85,1 & 107,3 & $54,7 \%$ & $51,0 \%$ & $54,7 \%$ & $54,1 \%$ \\
\hline 2011 & 1,09 & 2,48 & 84,8 & 109,9 & $59,8 \%$ & $51,6 \%$ & $59,8 \%$ & $48,1 \%$ \\
\hline 2012 & 1,11 & 2,83 & 92,0 & 117,7 & $59,6 \%$ & $53,2 \%$ & $59,6 \%$ & $50,5 \%$ \\
\hline 2013 & 1,18 & 3,10 & 95,8 & 110,8 & $61,8 \%$ & $51,1 \%$ & $61,8 \%$ & $54,6 \%$ \\
\hline 2014 & 1,23 & 3,26 & 99,1 & 112,2 & $70,9 \%$ & $51,5 \%$ & $70,9 \%$ & $57,6 \%$ \\
\hline "Mittelwert & $\overline{11,13}$ & 2,11 & 90,28 & 100,52 & 0,57 & 0,51 & 0,57 & $\overline{0,56}$ \\
\hline Median & 1,12 & 1,90 & 89,73 & 103,64 & 0,56 & 0,51 & 0,56 & 0,55 \\
\hline Spread*** & 0,14 & 1,79 & 18,74 & 36,63 & 0,15 & 0,01 & 0,15 & $-0,03$ \\
\hline Stan.-abw. & 0,05 & 0,57 & 6,95 & 12,07 & 0,05 & 0,02 & 0,05 & 0,05 \\
\hline Var.-koef. & 0,04 & 0,27 & 0,08 & 0,12 & 0,09 & 0,04 & 0,09 & 0,09 \\
\hline
\end{tabular}

Quelle: Deutsche Bundesbank, Schweizer Nationalbank, eigene Berechnungen

Hinweis: ** Differenz zwischen 2000 und 2014

36 Gischer/Richter (2014, 21f.) berechnen den adjustierten Personalaufwand ( $P A_{k, t}^{\text {adjust }}$. $)$ folgendermassen: $P A_{k, t}^{\text {adjust }}=\overline{P K_{t}} \cdot P B_{k, t}$, wobei $P B_{k, t}$ der Personalbestand der Bankengruppe $k$ zum Zeitpunkt $t$ und $\overline{P K_{t}}$ der standardisierte Personalkostensatz pro Kopf zum Zeitpunkt $t$ ist. Das jährliche Niveau der Personalaufwendungen pro Kopf der Landesbanken wird auf $100 \%$ normiert und dasjenige der Kantonalbanken entsprechend mit dem inversen Verhältnis der Personalkostensätze multipliziert. 
Hinsichtlich der in diesem Zuge kalkulierten Preissetzungsspielräume ${ }^{37}$ sind grosse Unterschiede zwischen Landes- und Kantonalbanken erkennbar. Während die eidgenössischen Institute über den Betrachtungszeitraum im Schnitt über $100 \%$ und in 2014 sogar mehr als $200 \%$ auf ihre Refinanzierungszinsen aufschlugen, konnten die Landesbanken im Mittel nur um 13 \% höhere Preise durchsetzen. ${ }^{38}$ Während dieser Sachverhalt unter sonst gleichen Bedingungen zu einer höheren CIR bei den Landes- im Vergleich zu den KB führt, wirkt das deutlich überdurchschnittliche Lohnniveau im Finanzsektor der Schweiz (BAKBASEL 2013, 27) - Tendenz zunehmend - entgegengesetzt auf die unbereinigte CostIncome-Ratio.

Während die unbereinigte CIR im gesamten Untersuchungszeitraum den KB eine höhere Leistungsfähigkeit attestiert, mündet die Berücksichtigung divergierender Preissetzungsspielräume und unterschiedlicher Personalkostensätze in einem differenzierten Bild. Mit Ausnahme des Jahres 2007 scheinen sich die eidgenössischen Banken erst seit 2010 und ab dann zunehmend von ihren deutschen Pendants abzusetzen. Trotz eines erheblich umfangreicheren Filialnetzes wiesen die KB in 2014 eine adjustierte CIR von 57,6 \% auf, die Landesbanken hingegen von 70,9\%. Offensichtlich erweist sich die Konzentration der schweizerischen Institute auf das klassische Kredit- und Einlagengeschäft trotz anhaltend niedrigen Leitzinsniveaus als nachhaltiges Geschäftsmodell.

\section{Zusammenfassung und Fazit}

Nicht zuletzt die internationale Finanzkrise hat offenbart, dass die Landesbanken in ihrer gegenwärtigen Marktposition nur schwer überlebensfähig sein werden. Die Suche nach einem nachhaltig tragfähigen Geschäftsmodell ist daher allgegenwärtig und unverändert Gegenstand zahlreicher wissenschaftlicher Untersuchungen. Um normative Rückschlüsse ziehen zu können, bedarf es jedoch einer möglichst präzisen Erfassung und Abgrenzung verschiedener Geschäftsmodelltypen. Nur so können Alternativen zielführend gegeneinander abgewogen werden. Genau dahingehend bleiben gängige Untersuchungen jedoch weitgehend unbestimmt. Je nach Intention des jeweiligen Verfassers werden unterschiedliche Merkmale in den Mittelpunkt gerückt und verschiedene Kennzahlen ausgewertet ohne wissenschaftlich stringent abgeleitete Grenzen zur Unterscheidung der Geschäftsmodelle im Sinne einer Benchmark zu nutzen.

Dahingehend adressiert der Beitrag - konzeptionell — eine innovative Methodik zur strukturierten, harmonisierten Bestandsaufnahme von Geschäftsmodellen: einen referenzwert-gestützten Cluster-Algorithmus. Eingebettet in einen dreistufigen, ineinandergreifenden Analyseprozess wird ferner der Frage nachgegangen, inwieweit die mit ähnlichen Auf-

37 Die Preise ergeben sich als Relation von Zinserträgen zu den zinstragenden Aktiva; die Grenzkosten entsprechend als Zinsaufwendungen im Verhältnis zu den zinstragenden Passiva (Gischer/Richter 2014, 14f.).

38 Gischer/Richter (2014, 19ff.) leiten daraus einen adjustierten Zinsüberschuss $\left(Z \ddot{U}_{k, t}^{\text {adjust. }}\right)$ der folgenden Gestalt her: $Z \ddot{U}_{k, t}^{\text {adjust }}=Z A_{k, t} \cdot\left(\overline{M_{t}} \cdot\left(\frac{A_{k, t}}{P_{k, t}}\right)-1-R V_{k, t}\right)$, wobei die Zinsaufwendungen $\left(Z A_{k, t}\right)$, die zinstragenden Aktiva $\left(A_{k, t}\right)$, die zinstragenden Passiva $\left(P_{k, t}\right)$, die Risikovorsorge $\left(R V_{k, t}\right)$ sowie der standardisierte Mark-Up $\left(\overline{M_{t}}\right)$ der Bankengruppe $k$ zum Zeitpunkt $t$ zur Berechnung benötigt werden. Um den standardisierten Mark-Up zu erhalten, wird in der vorliegenden Arbeit der Preissetzungsspielraum der Landesbanken auf $100 \%$ normiert und derjenige der Kantonalbanken entsprechend angepasst. „In der Konsequenz erfolgt die Berechnung der CIR unter Annahme identischer Preissetzungsspielräume bzw. Wettbewerbsverhältnisse“. (Gischer/Richter 2014, 20). 
gaben betrauten schweizerischen KB als geschäftsstrategisches Vorbild für die Gruppe der Landesbanken dienen können.

Im ersten Schritt wird der grundsätzliche Homogenitätsgrad der untersuchten Banken untersucht. Diesbezüglich legt die dezidierte Aufarbeitung der nationalen Rahmenbedingungen, zentralen Charakteristika und Alleinstellungsmerkmale beider Bankengruppen offen, dass die deutschen Landesbanken erhebliche Parallelen untereinander und auch im Vergleich zu den Kantonalbanken hinsichtlich der Trägerschaft, der Einbindung in eine Verbundstruktur und vor allem der grundsätzlich gemeinwohlorientierten Geschäftsausrichtung aufweisen. Vor diesem Hintergrund gehen die acht Landesbanken ebenso wie die 24 Kantonalbanken im gewichteten Aggregat, mithin als jeweilige Gruppe, in die weiteren Analyseschritte ein. Der Verzicht auf 168 Einzelinstituts-Vergleichen stellt so eine sinnvolle Interpretierbarkeit der Ergebnisse sicher.

Im zweiten Schritt schliesst sich nunmehr die Einordnung der Geschäftsmodelle beider Bankengruppen selbst an. Anhand deskriptiver Statistiken werden zunächst die jeweiligen Geschäftsfelder einführend beleuchtet. Als Herzstück des Beitrages schliesst sich dann die Identifizierung und kategorisierende Einordnung der Geschäftsmodelle im Zeitverlauf (2000, 2007, 2014) auf Basis eines referenzwert-gestützten Clusteralgorithmus nach Ayadilde Groen (2014) bzw. Roengpitya et al. (2014) an.

Es zeigt sich, dass sich die Landesbanken als am „Interbanken-/ Kapitalmarkt refinanzierte" Geschäftsbank noch immer wesentlich stärker im Zwischenbankgeschäft engagieren als KB. Gleichwohl ist im Nachgang an die Finanzkrise eine vorsichtige Trendwende im Sinne einer Reduzierung der Kapitalmarktgeschäfte erkennbar. So sank der Anteil der Aktiva in Form von handelbaren Wertpapieren von 2007 bis 2014 auf unter 50 \%. Das Geschäftsmodell der KB kann hingegen durchweg als am „Retailgeschäft fokussiert“ kategorisiert werden. Mithin ist für sie das klassische Intermediationsgeschäft mit Kundeneinlagen als wichtigste Refinanzierungsform prägend.

Im dritten und letzten Schritt wird nunmehr untersucht, ob die identifizierten (Unterschiede der) Geschäftsmodelle mit systematischen Unterschieden in der Leistungsfähigkeit beider Bankengruppen einhergehen, um so normative Rückschlüsse auf eine gegebenenfalls zu empfehlende Neuausrichtung machen zu können. Die Ergebnisse legen den Schluss nahe, dass sich die geschäftspolitischen Unterschiede auch in der langfristigen Performance (2000-2014) der Institutsgruppen niederschlagen. Während sich der Jahresüberschuss (v. S.) der KB in den vergangenen 10 Jahren konstant auf einem hohen Niveau bewegte, fiel dieser bei den Landesbanken deutlich volatiler und teilweise negativ aus. Auch die nahezu durchweg höheren Eigenkapital- und im Zeitablauf stabileren Gesamtkapitalrenditen sprechen ebenso wie die höheren Eigenkapitalquoten und Z-Scores für die überlegene Risikotragfähigkeit der KB gegenüber den LB.

In Hinblick auf die Wirtschaftlichkeit / Produktivität beider Bankengruppen zeigt sich ein differenziertes Bild, sobald das wettbewerbsintensivere Umfeld in Deutschland und das höhere Lohnniveau in der Schweiz bei der Kalkulation der Cost-Income-Ratio Berücksichtigung finden. Die entsprechend adjustierte CIR (nach Gischer/Richter (2014)) zeigt, dass die KB ihre relative Position gegenüber den LB im Zeitverlauf seit 2004 merklich verbessern konnten. Zuvor mussten die KB noch erkennbar mehr Verwaltungsaufwendungen als die LB einsetzen, um einen Euro bzw. Schweizer Franken an Ertrag zu generieren. Die KB erweisen sich daher in mehrerlei Hinsicht als leistungsfähiger als die LB. 
Schlussfolgerungen

Die Clusteranalyse gepaart mit einer adjustierten Leistungsmessung legen mehrere Schlussfolgerungen nahe: Zum einen ähnelt das Geschäftsmodell der KB trotz vieler Gemeinsamkeiten zu den LB eher in der Ausrichtung grossen deutschen Sparkassen mit einem starken Fokus auf das Retailgeschäft. Zum anderen scheint die Fokussierung auf ein spezielles Geschäftsfeld im Allgemeinen und auf das klassische Kreditgeschäft im Besonderen langfristigen Erfolg sichern zu können. Zwar steht den LB der Weg in das Retailgeschäft aufgrund der tieferen vertikalen Subsidiarität nicht bzw. nur punktuell offen. Aber eine grundsätzliche Neuausrichtung orientiert am tatsächlichen Bedarf, welcher von den verbundenen Sparkassen und sonstigen Instituten bzw. von Privat-, Firmen- und öffentlichen Kunden reklamiert, aber von anderen Finanzinstitutionen nicht gedeckt wird, erscheint zielführend. So könnte die Rückbesinnung auf das klassische Verbundgeschäft (Sparkassenzentralbank) das mittelstandsnahe Firmenkundengeschäft, Leistungen für private Grossvermögen sowie Auslandsbetreuung von Firmenkunden, inländisch gewerbliche Immobilienfinanzierung, ein das Firmenkundengeschäft unterstützendes Kapitalmarktgeschäft und Asset-Management Kernpunkte einer nachhaltigen geschäftsstrategischen Ausrichtung für die Zukunft sein. Wesentlich ist dabei die Spezialisierung. Nur darüber können im Zeitablauf wertvolle Erfahrungs- und Wissensvorsprünge erreicht werden und insofern ein nachhaltiger Wettbewerbsvorteil. Das kurzfristige Ausweichen auf hoch risikoträchtige Aktivitäten im breitflächigen Kreditersatzgeschäft hat sich indes nicht nur als nicht zielführend erwiesen, sondern steht auch im Konflikt mit der Gemeinwohlorientierung öffentlich-rechtlicher Banken.

Insgesamt darf eine Neuorganisation des Landesbankensektors keinesfalls ohne Berücksichtigung der gruppenspezifischen Abhängigkeiten und des mit dem öffentlich-rechtlichen Hintergrund verbundenen Gemeinwohlauftrages erfolgen. Sollte sich der Markt in dieser Form als zu eng erweisen, ist eine weitergehende Konsolidierung zwingend. Da es sich bei den LB aber auch um (ehemalige) Prestigeobjekte der sie mittragenden Bundesländer handelt, steht zu befürchten, dass politische Hindernisse einer „Neustrukturierung“ im Wege stehen könnten.

\section{Literaturverzeichnis}

Altunbas, Y./Manganelli, S./Marques-Ibanez, D. (2011): Bank risk during the financial crisis: Do business models matter?, ECB Working Paper Series, Nr. 1394, Frankfurt am Main.

Arrawatia, R./Misra, A. (2012): Competition in Banking Industry: A literature Review, in: International Journal of Commerce Business and Management, 1. Jg., Heft 3, S. 23192828 .

Auerbach, C./Schiereck D. (2013): Refinanzierungsherausforderungen der Sparkassen und das Potenzial von Pfandbriefemissionen: Erkenntnisse einer ersten Umfrage unter 170 Instituten, in Zeitschrift für das gesamte Kreditwesen, Jg. 66, Heft 2, S. 90

Ayadi, R./De Groen, W. (2014): Banking Business Models Monitor 2014: Europe, in: Center for European Policy Studies and International Observatory on Financial Services Cooperatives, Brüssel u. a.

Ayadi, R./De Groen, W./Sassi I./Mathlouthi, W./Rey, H./Aubry, O. (2017): Banking Business Models Monitor 2015: Europe,. HEC Montreal 
Ayadi, R./Schmidt, R./Carbó-Valverde, S. (2009): Investigating Diversity in the Banking Sector in Europe: The Performance and Role of Savings Banks, in: Centre for European Policy Studies, Brüssel.

BAKBASEL Economics (2013): Finanzplatz Schweiz - Volkswirtschaftliche Bedeutung und Wechselwirkungen mit dem Werkplatz: Eine Analyse im Auftrag der Schweizerischen Bankiervereinigung und economiesuisse, März, Basel.

Bain, J. (1951): relation of Profit Rate to Concentration: American Manufacturing, 1936-1940, in: Quarterly Journal of Economics, 65 JG., Heft 3, S. 293-324

Beck, T./Demirgüc-Kunt A./Merrouche O. (2013): Islamic vs. conventional banking: Business model, efficiency and stability, in: Journal of Banking \& Finance, 37 Jg., Heft 2, S. 433-447.

Berge, K./Berger, R./Locarek-Junge, H. (2006): Deutsche Landesbanken: Status Quo und Strategien vor dem Hintergrund des Wegfalls der Staatsgarantien, in: Vierteljahreshefte zur Wirtschaftsforschung, 75. Jg., Heft 4, S. 73-92.

Blundell-Wignall, A./Roulet, C. (2013): Business models of banks, leverage and the distance-to-default, in: Financial Markets Trends, 2. Jg., OECD.

Brämer, P. (2015): Erklärungsansätze für die Krisenresistenz der australischen Banken, Hamburg.

Brämer, P./Gischer, H./Richter, T. (2010a): Das deutsche Bankensystem im Umfeld der internationalen Finanzkrise, in: List Forum für Wirtschafts- und Finanzpolitik, 36. Jg., Heft 4, S. 318-334.

Brämer, P./Gischer, H./Richter, T. (2010b): Quo vadis Landesbanken? in: Jahrbuch des Föderalismus 2010 - Föderalismus, Subsidiarität und Regionen in Europa, hrsg. von Rudolf Hrbek, Baden-Baden, S. 200-211.

Brämer, P./Gischer, H./Pfingsten, A./Richter, T. (2010c): Der öffentliche Auftrag der deutschen Sparkassen aus der Perspektive des Stakeholder-Managements, in: Zeitschrift für öffentliche und gemeinwirtschaftliche Unternehmen, 33. Jg., Heft 4, S. 313-334.

Burger, A. (2008): Produktivität und Effizienz in Banken: Terminologie, Methoden und Status quo, Working Paper Series, Nr. 92, Frankfurt School of Finance \& Management.

Burger, A./Moormann, J. (2008): Productivity in banks: myths \& truths of the Cost Income Ratio, in: Banks and Bank Systems, 3. Jg., Heft 4, S. 85-94.

Deutsche Bundesbank (2014): Die Ertragslage der deutschen Kreditinstitute im Jahr 2013, Monatsbericht, September, S. 55-78.

Deutsche Bundesbank (2015): Strukturelle Entwicklungen im deutschen Bankensektor, Monatsbericht, April, S. 33-59.

Deutscher Sparkassen- und Giroverband (2012): Mittel für Verbundbank bestätigt, Pressemitteilung Nr. 33/2012 vom 19. März 2012, Berlin.

Deutscher Sparkassen- und Giroverband (2013): Deutscher Bankenmarkt: robust und leistungsfähig, AktuellerStandpunkt, Nr. 2013/05, November, Berlin.

Deutscher Sparkassen- und Giroverband (2014a): Sparkassen-Finanzgruppe in Zahlen 2014, http://www.dsgv.de/de/sparkassen-finanzgruppe/daten-und-fakten/index.html\# (Zugriff: 3.8.2015).

Deutscher Sparkassen- und Giroverband (2014b): Die Pfandbrief-Sparkassen 2014, Berlin.

Deutscher Sparkassen- und Giroverband (2014c): Schweizer Kantonalbanken neue Mitglieder im DSGV, Pressemitteilung Nr. 31/2014 vom 31. März 2014, Berlin. 
Deutscher Sparkassen- und Giroverband (2015): DSGV-Mitgliederversammlung beschliesst Anpassung des Sicherungssystems, Pressemitteilung Nr. 35/2015 vom 21. Mai 2015, Berlin.

Engerer, H. (2006): Vom Dreisäulensystem zum Baustein des europäischen Hauses: Wandel von Eigentum und Wettbewerb im deutschen Bankensektor, in: Vierteljahreshefte zur Wirtschaftsforschung, 75. Jg., Heft 4, S. 11-32.

Engerer, H./Schrooten, M. (2004): Untersuchung der Grundlagen und Entwicklungsperspektiven des Bankensektors in Deutschland (Dreisäulensystem), Gutachten im Auftrag des Bundesministeriums für Finanzen, Deutsches Institut für Wirtschaftsforschung, Juni, Berlin.

Ewert, R./Wagenhofer, A. (2008): Interne Unternehmensrechnung, 8. Aufl., Heidelberg [u. a.]

Flesch, J. (2010): Landesbanken ohne neues Geschäftsmodell, in: Zeitschrift für das gesamte Kreditwesen, 63. Jg., Heft 4, S. 172-176.

Gischer, H./Richter, T. (2011): Konsolidierung, Effizienz und Stabilität: Sind grosse Banken leistungsfähiger als kleine? in: Jahrbuch für Wirtschaftswissenschaften, 62. Jg., Heft 2, S. 172-195.

Gischer, H./Richter, T. (2014): Produktivitätsmessung von Banken: die Cost Income Ratio - ein belastbares Performancemass? FEMM Working Paper, Nr. 8/2014, Otto-vonGuericke-Universität, Magdeburg.

Greiling, D. (2007): Perfomance Measurment in Nonprofit Organisationen, Mannheim.

Gubitz, B. (2013): Das Ende des Landesbankensektors - Der Einfluss von Politik, Management und Sparkassen, Wiesbaden.

Hartmann-Wendels, T./Pfingsten, A./Weber, M. (2014): Bankbetriebslehre, 6. Auflage, Berlin.

Hess, H. (2008): Strategie und Entwicklung der Kantonalbanken, in: Zeitschrift für das gesamte Kreditwesen, 61. Jg., Heft 19, S. 974-976.

Hess, H. (2014): Kantonalbanken: Stütze der Schweizer KMU-Wirtschaft, in: Zeitschrift für das gesamte Kreditwesen, 67. Jg., Heft 14, S. 719-722.

Hoffmann, M./Morkoetter, S. (2011): Swiss Cantonal Banks: Safe Haven in a Rough Sea?, in: Revue bancaire et financière, 75. Jg., Heft 3, S. 145-149.

Johnes, J./Izzeldin, M./Pappas V. (2014): A comparison of performance of Islamic and conventionalbanks 2004-2009, in: Journal of Economic Behavior \& Organization, 103 Jg., Sonderheft, S. 93-107

Kaulvers, S. (2015): Strategische Ausrichtung einer Landesbank im Spannungsfeld von Ertrag und Eigenkapital, in: Neuausrichtung der Banken - Auf der Suche nach Ertragsquellen und Eigenkapital, hrsg. von Werner Böhnke und Bernd Rolfes, Wiesbaden, S. 2940.

Kühlwein, A./Burkert, U. (2015): Bankanalyse - wachsende Bedeutung seit der Finanzkrise, in: Bankenrating, hrsg. von Oliver Everling und Karl-Heinz Goedeckemeyer, 2.Aufl., Wiesbaden, S. $157-184$.

Lampert, S. (2010): Der öffentliche Auftrag der Landesbanken - Verfassungs-, europaund landesrechtliche Vorgaben für die Betätigung der Landesbanken, in: Deutsches Verwaltungsblatt, 125. Jg., Heft 23, S. 1466-1474.

Lerner, A. (1934): The Concept of Monopoly and the Measurement of Monopoly Power, in: Review of Economic Studies, 1Jg. Heft 3, 157-175 
Köhler, M. (2015): Which banks are more risky? Retail- versus investment-oriented banks, Journal of Financial Stability

Koetter, M. (2008): An Assessment of Bank Merger: Success in Germany, in: German Economic Review, 9 Jg., Heft 2, 232-264

Martìn R./Marqués Sevillano, J. (2011): Copperative and savings banks in Europe: nature, challenges and perspectives, Banks and Bank Systems, 6. Jg., Heft 3, S. 121-135.

Mason E. (1939), Price and Production policies of Large-Scale Enterprise, in: American Economic Review, 29 Jg., Heft 1, S. 61-74

Meier, H./Marthinsen, J./Gantenbein, P. (2013): Swiss Finance: Capital Markets, Banking, and the Swiss Value Chain, Hoboken, N. J.

Neumann, M. (2000): Wettbewerbspolitik, Wiesbaden.

Noack, H. (2009): Back to the roots - Konsolidierung als kompetenter Partner der Sparkassen, in: Die Zukunft der Landesbanken - Zwischen Konsolidierung und neuem Geschäftsmodell, hrsg. von Friedrich-Ebert-Stiftung, Expertisen und Dokumentationen zur Wirtschafts- und Sozialpolitik, Dezember, Bonn, S. 5-19.

Pfingsten,A. /Bélorgey, C./Hesse, F. (2014): Konzeptionelle Überlegungen und empirische Befunde zum Outsourcing des Problemkreditgeschäfts in Genossenschaftsbanken und Sparkassen, in: Zeitschrift für öffentliche und gemeinwirtschaftliche Unternehmen, 37. Jg., Heft 3, S. 153-168.

Piazza, D. (2012): Dimensionen zur Positionierung der Public Corporate Governance bei Kantonalbanken zwischen Politik und Ökonomie, Dissertation Nr. 4036 der Universität St. Gallen.

Richter, T. (2013): Zur Performancemessung im Bankensektor: Wettbewerbs- und Produktivitätsverhältnisse im innereuropäischen Vergleich, Berlin.

Roengpitya, R./Tarashev, N./Tsatsaronis, K. (2014): Bank business models, in: BIS Quarterly Review, Dezember, S. 55-65, http://www.bis.org/publ/qtrpdf/r_qt1412g.pdf (Zugriff: 9.6.2015).

Rudowicz, J. (2013): Die Krise der BayernLB: Können wir auf die Landesbank verzichten? in: Zeitschrift für Außen und Sicherheitspolitik, 6. Jg., Heft 1, 43-51.

Sachverständigenrat (2008): Das deutsche Finanzsystem: Effizienz steigern - Stabilität erhöhen: Expertise im Auftrag der Bundesregierung, Juni.

Schackmann-Fallis, K./Weiß, M. (2009): Landesbanken und Sparkassen - Die Zukunft des öffentlich-rechtlichen Bankensektors, in: Jahrbuch Bitburger Gespräche 2009 I, Trier, S. 85-100.

Schaeck, K./Čihák, M. (2008): How does competition affect efficiency and soundness in banking?, ECB Working Paper Series, Nr. 932, September, Brüssel.

Schildbach, J. (2008): European banks: The silent (r)evolution, in: Deutsche Bank Research, EU-Monitor, Finanzmarkt Spezial, Nr. 54, 1-31.

Schrooten, M. (2009a): Landesbanken: Zukunft ungewiss, in: Wirtschaftsdienst, 89. Jg., Heft 10, S. 666-671.

Schrooten, M.(2009b): Landesbanken - Tragfähiges Geschäftsmodell gesucht, in: Die Zukunft der Landesbanken - Zwischen Konsolidierung und neuem Geschäftsmodell, hrsg. von Friedrich-Ebert-Stiftung, Expertisen und Dokumentationen zur Wirtschafts- und Sozialpolitik, Dezember, Bonn, S. 20-33.

Schweizer Nationalbank (2014): Die Banken in der Schweiz 2014, Jg. 99, https:/www.s nb.ch/ext/stats/bankench/pdf/defr/Die_Banken_in_der_CH.book.pdf (Zugriff: 24.8.2015). 
Schwitter, G. (2000): Die Privatisierung von Kantonalbanken: Rechtliche Aspekte der Privatisierung öffentlicher Unternehmen unter besonderer Berücksichtigung der Kantonalbanken, Universitätsverlag Freiburg Schweiz.

Siekmann, H. (2011): Die rechtliche Regulierung öffentlicher Banken in Deutschland, Institute for Monetary and Financial Stability, Working Paper Series, Nr. 48, Frankfurt am Main

Staats, S. (2006): Fusionen bei Sparkassen und Landesbanken: Eine Untersuchung zu den Möglichkeiten der Vereinigung öffentlich-rechtlicher Kreditinstitute, Berlin.

Varmaz, A. (2006): Rentabilität im Bankensektor, Bremen.

Verband Schweizerischer Kantonalbanken (2013): Die Kantonalbanken in Zahlen, http:/ /kantonalbank.com/_files/mediencenter/publikationen/2014/VSKB_KB-in-Zahlen-2013.pd f (Zugriff: 20.5.2015).

Von Zanthier, U. (2015): Analyse und Beurteilung von Geschäftsmodellen, in: Bankenrating, hrsg. von Oliver Everlin und Karl-Heinz Goedeckemeyer, 2. Aufl., Wiesbaden, S. 39-54.

Vögeli, A. (2009): Staatsgarantie und Leistungsauftrag bei Kantonalbanken, Zürich u.a.

Ward, J. H. (1963): Hierarchical Grouping to Optimize an Objective Function, in: Journal oft he American Statistical Association, 58 Jg., Heft 301, S. 236-244

Zentrum für Europäische Wirtschaftsforschung GmbH (2012): Risikoübernahme im Bankensektor: Unterscheiden sich Sparkassen und Genossenschaftsbanken von Geschäftsbanken? Untersuchung für die Wissenschaftsförderung der Sparkassen Finanzgruppe e.V., Mannheim. 


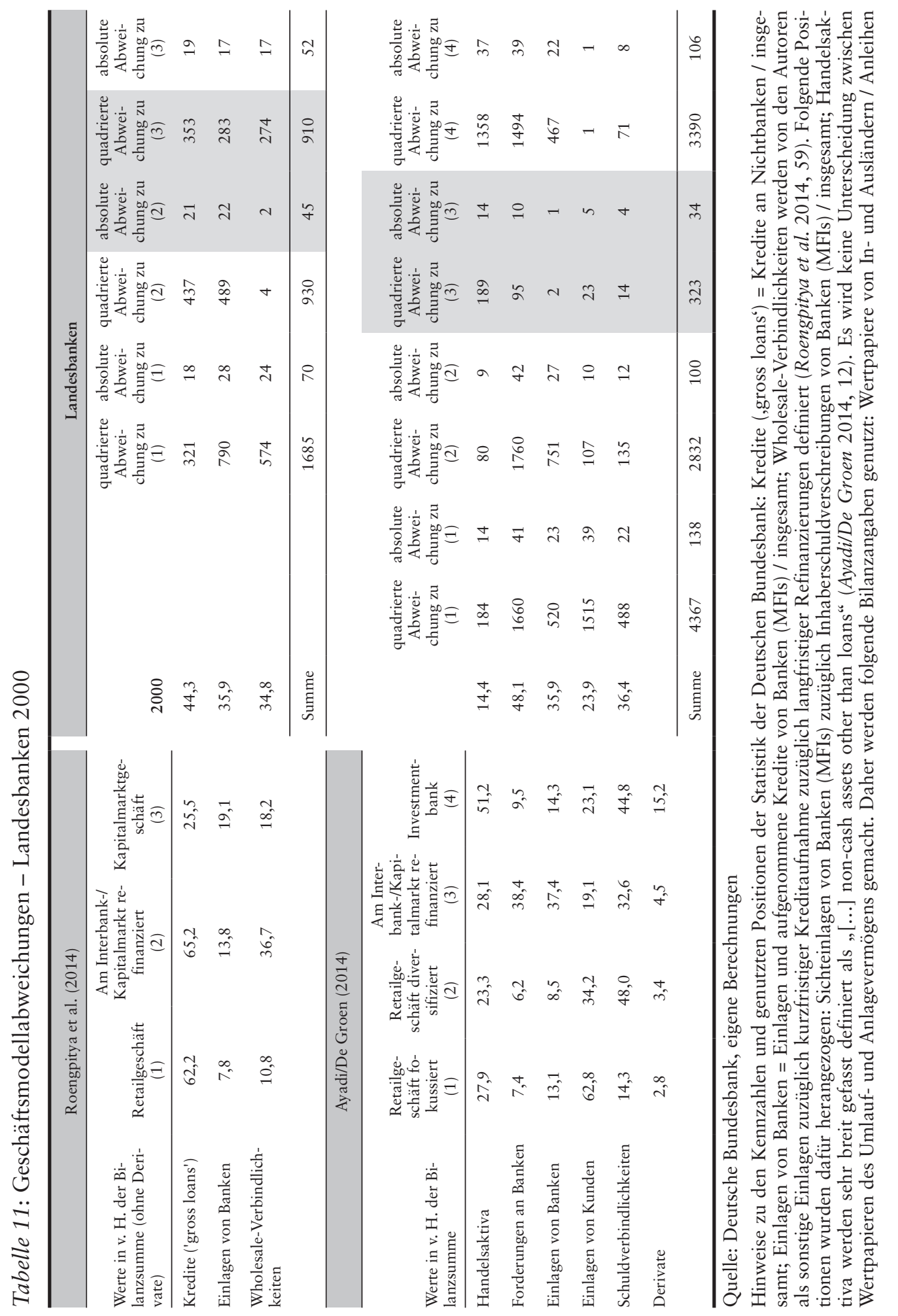




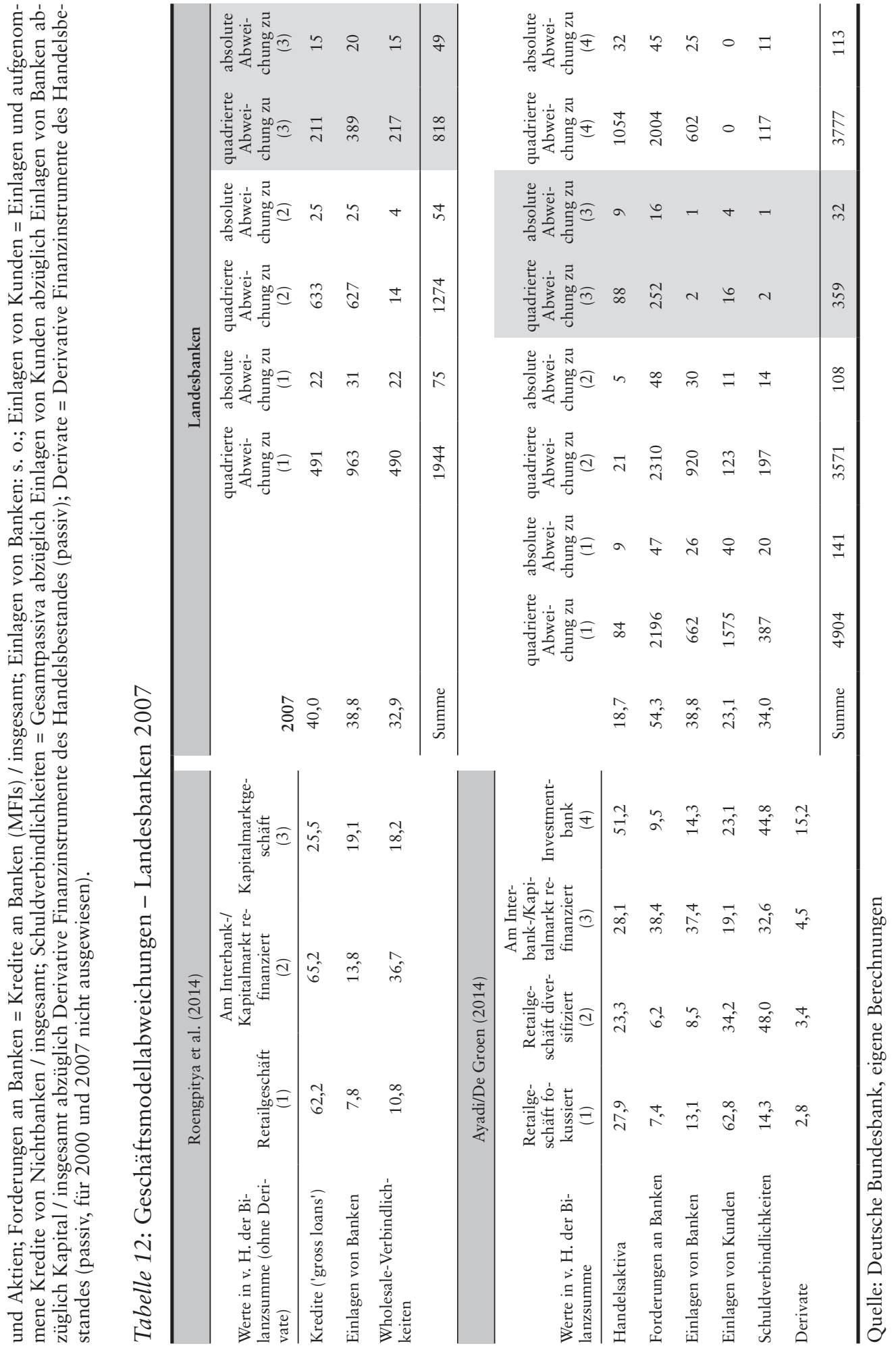




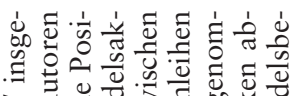

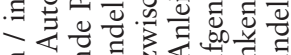

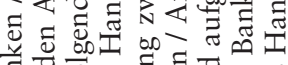

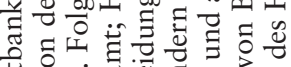

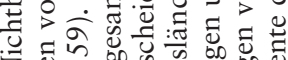

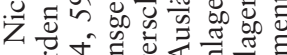

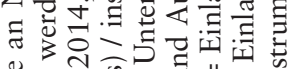
o

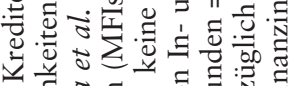

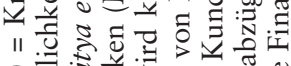

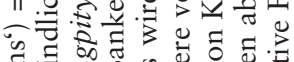

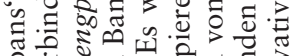

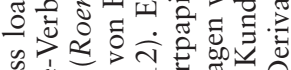

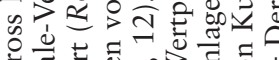

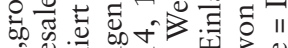

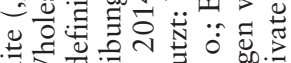
들 政

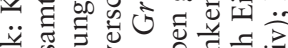

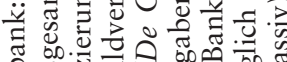

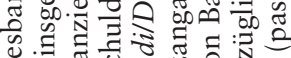
원를

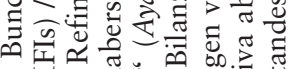

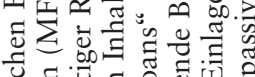

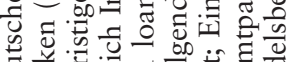

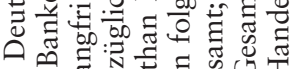
我政

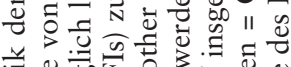
흘

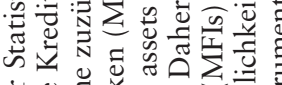

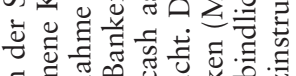
5

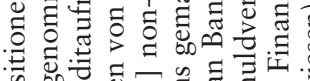

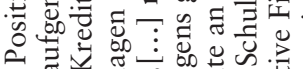
50.

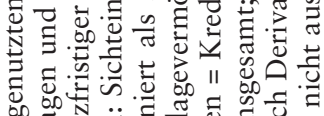
o d o

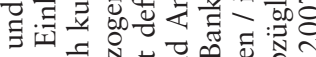

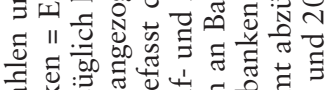

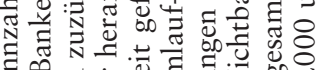
言呟 일

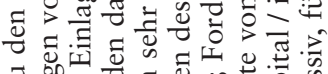

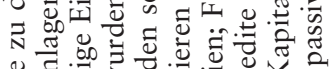

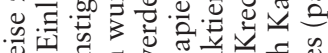

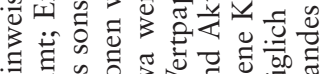

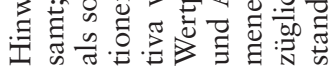

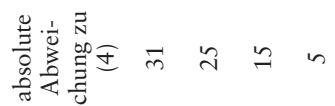

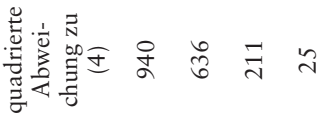

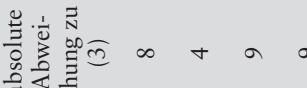

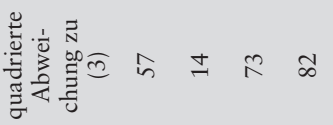

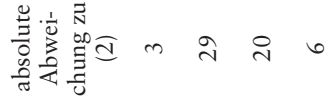

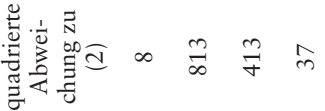

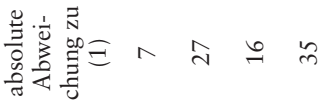

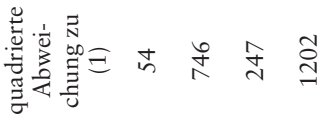

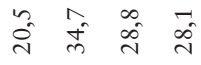

莺泀无

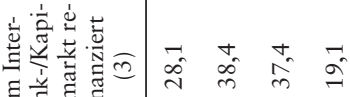

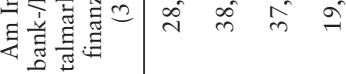

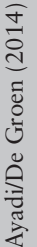

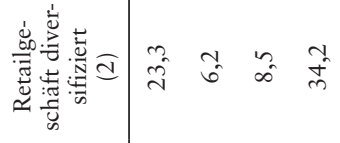

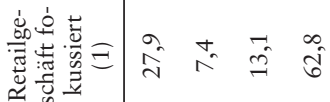

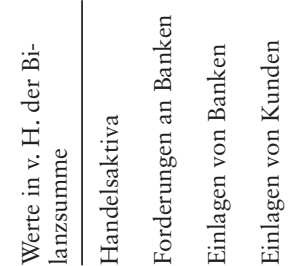



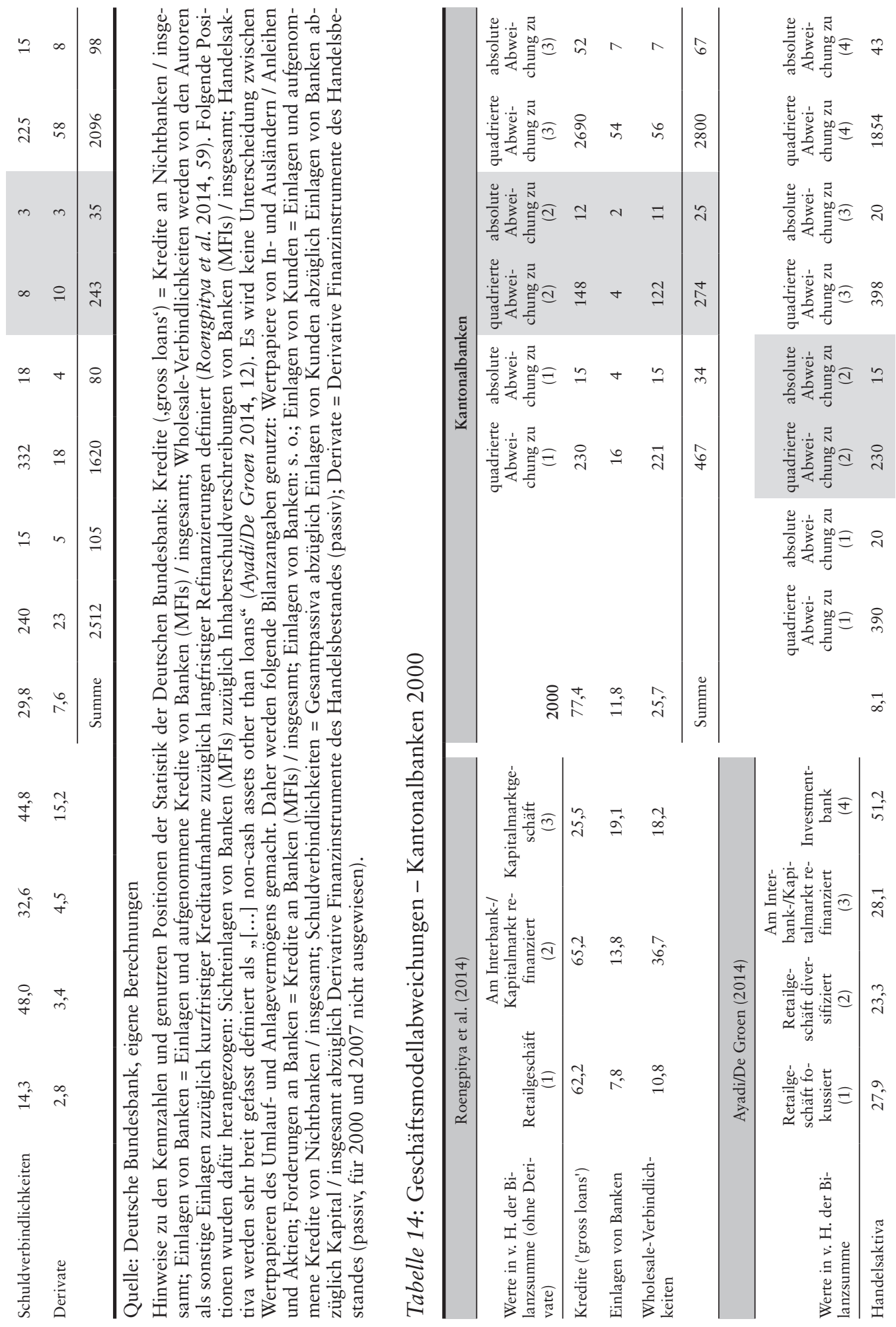


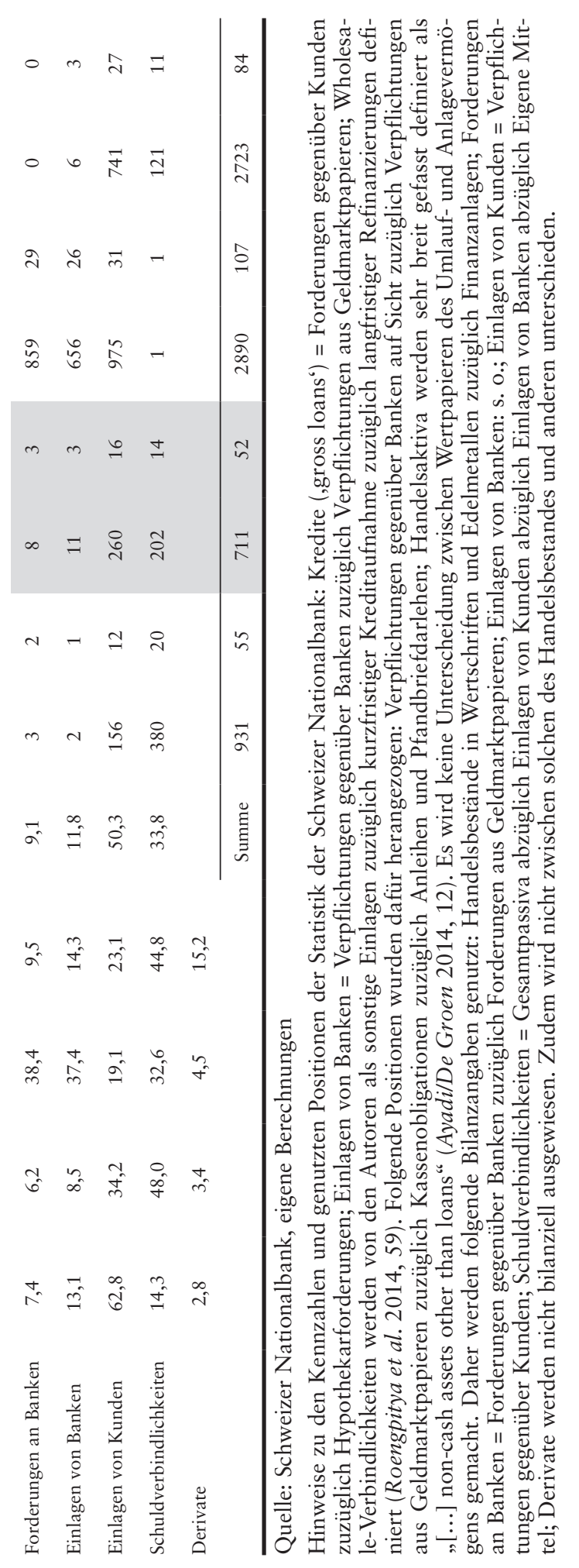

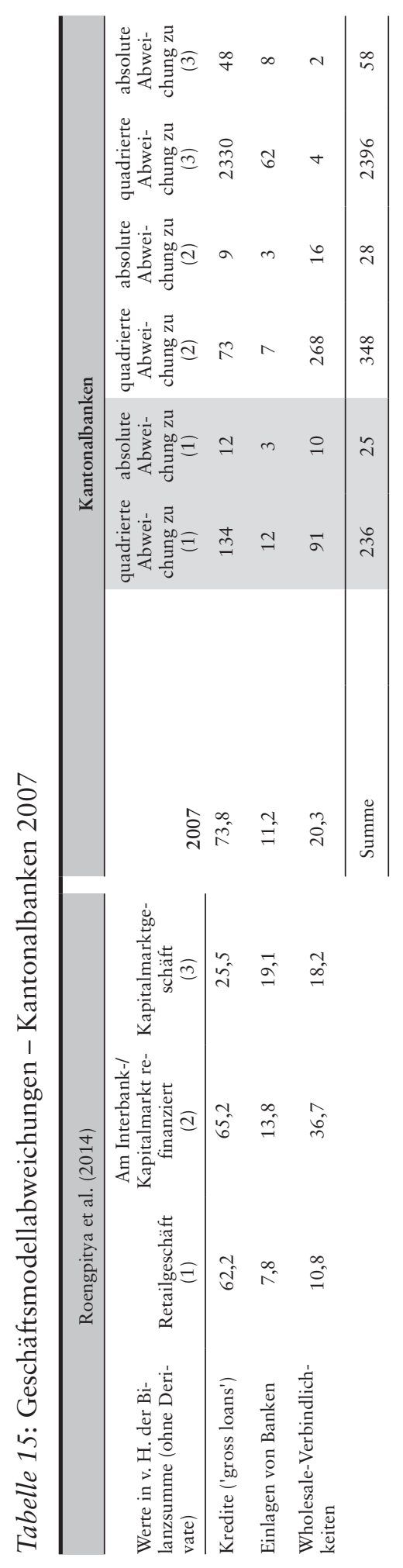

Die Unternehmung, 73. Jg., 1/2019 


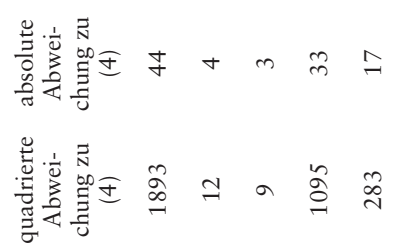

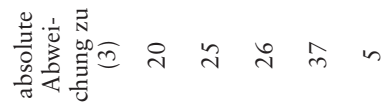

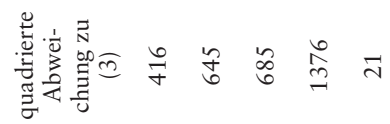

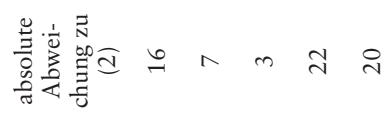

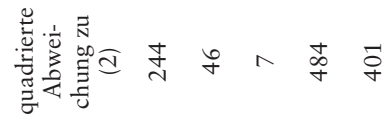

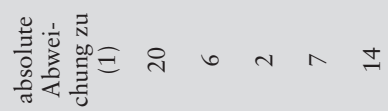

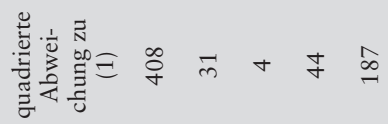

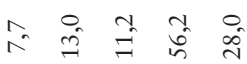

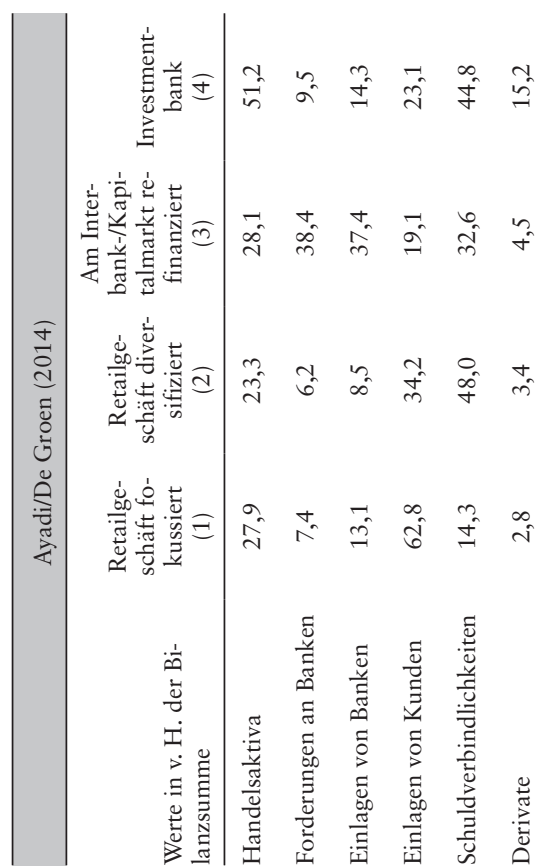

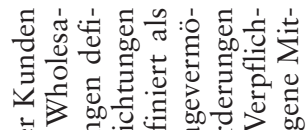

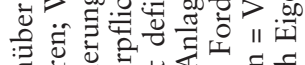

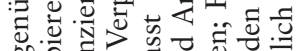

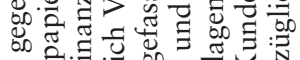

娄

$\stackrel{\Xi}{\exists}$

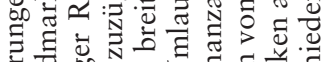

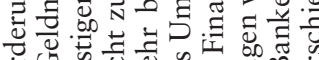

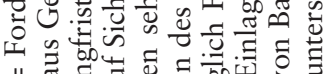

$\frac{m}{m}$

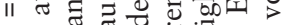

क力

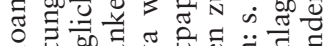

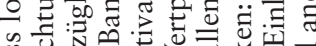

象号 N

6.

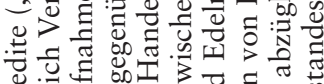

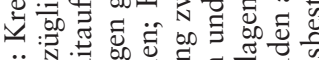

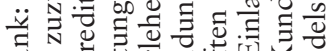

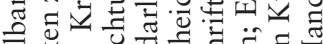

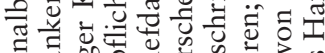

응.

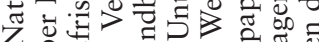

茤

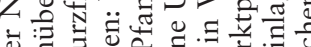

충

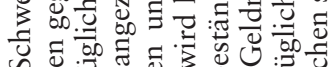

㻤:

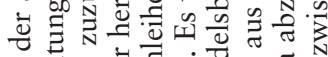

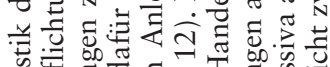

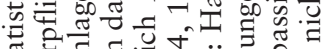

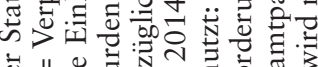

䓀 $11.00 \%$

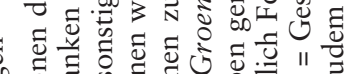

政

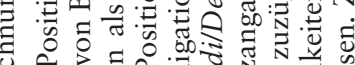

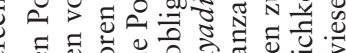

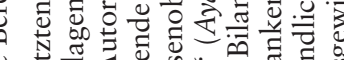

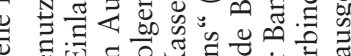

㟧

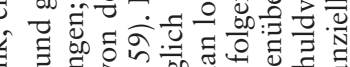

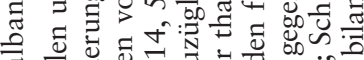

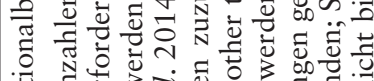

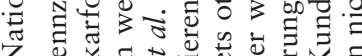

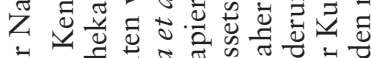

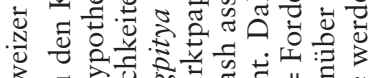

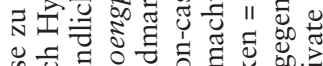

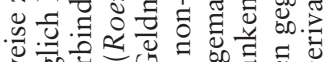

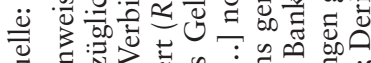

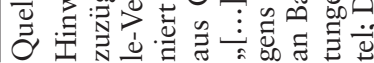

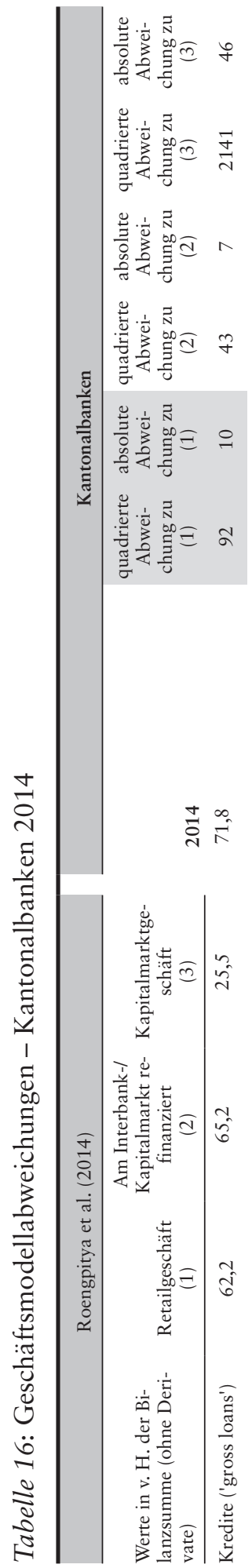




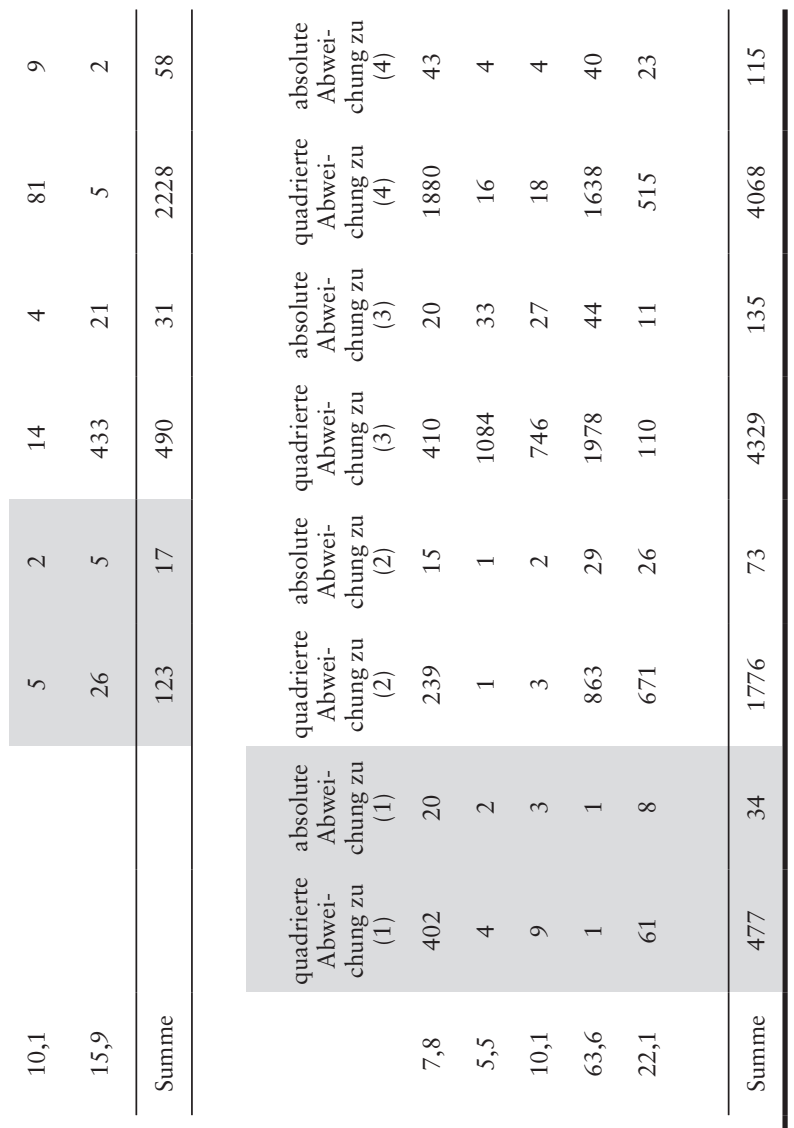

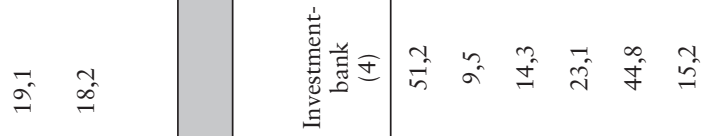

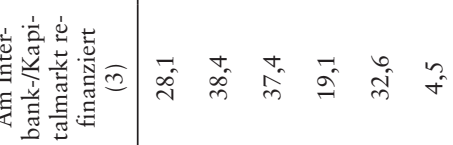

$\stackrel{\infty}{\stackrel{n}{\sim}}$

$\stackrel{\infty}{\wedge} \stackrel{\infty}{\infty}$

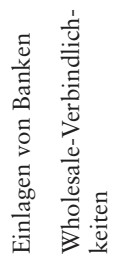

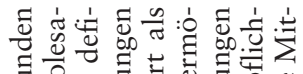

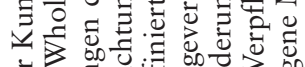

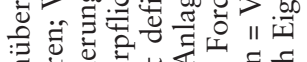

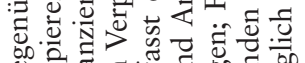

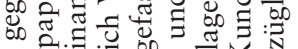

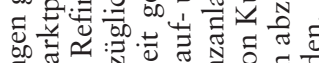

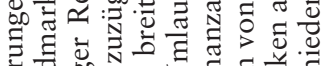

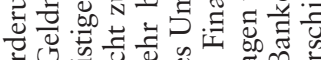

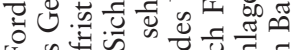

II

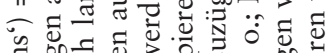

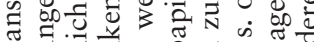

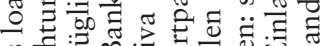

记 :

to 0 讨

잉 : : :

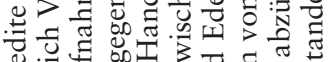

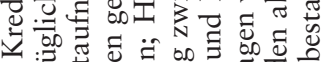

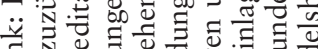

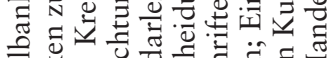

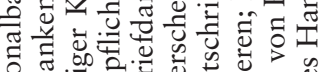

음 00000

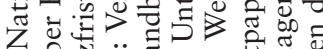

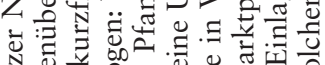

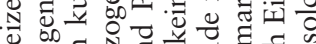

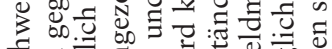

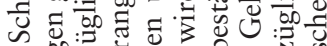

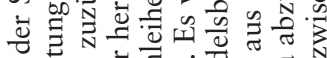

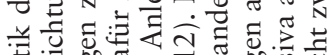

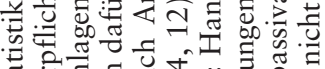

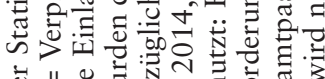

芩 11.00

牙苟

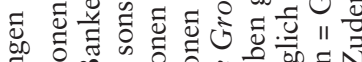

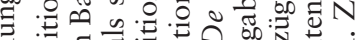

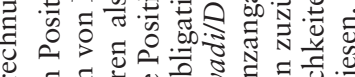

过

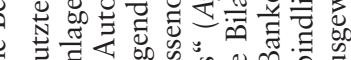

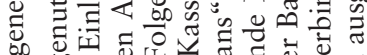

㐘

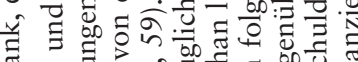

䒕

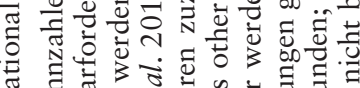

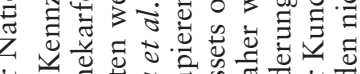

虫

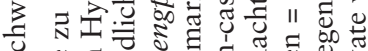

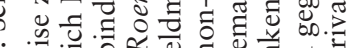

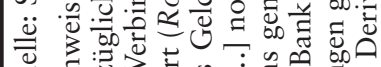

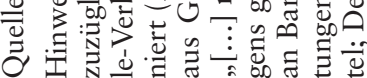


Toni Richter, Dr., ist wissenschaftlicher Mitarbeiter an der Fakultät für Wirtschaftswissenschaft der Otto-von-Guericke-Universität in Magdeburg, E-Mail: toni.richter@ovgu.de

Horst Gischer, Prof. Dr., ist Lehrstuhlinhaber an der Fakultät für Wirtschaftswissenschaft der Otto-von-Guericke-Universität in Magdeburg und geschäftsführender Direktor des Forschungszentrums für Sparkassenentwicklung e.V., E-Mail: horst.gischer@ovgu.de

Florian Schierhorn, M.Sc., ist Mitarbeiter an der NORD/LB in Hannover

Anschrift: Otto-von-Guericke-Universität Magdeburg, Fakultät für Wirtschaftswissenschaft (FWW), Lehrstuhl für Monetäre Ökonomie und öffentlich-rechtliche Finanzwirtschaft, Universitätsplatz 2, D-39106 Magdeburg, Tel.: +49 (0) 391/6701 